April 1999 - NREL/SR-550-26485

\title{
Report on Solar Pool Heating Quantitative Survey
}

\section{August 1998 - December 1998}

Synapse Infusion Group, Inc. Westlake Village, California

. 


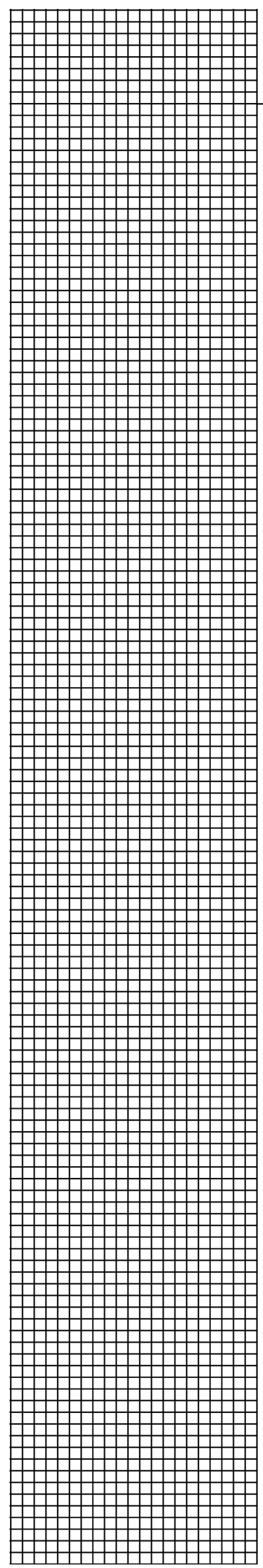

April 1999 • NREL/SR-550-26485

\section{Report on Solar Pool Heating Quantitative Survey}

\section{August 1998 - December 1998}

Synapse Infusion Group, Inc. Westlake Village, California

NREL Technical Monitor: R. Hewett

Prepared under Subcontract No. AAR-8-18482-01

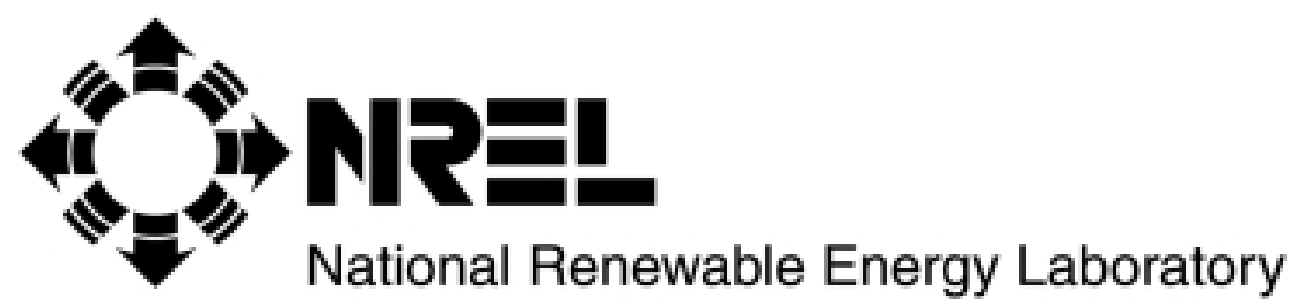

1617 Cole Boulevard

Golden, Colorado 80401-3393

NREL is a U.S. Department of Energy Laboratory

Operated by Midwest Research Institute - Battelle • Bechtel

Contract No. DE-AC36-98-G010337 


\section{NOTICE}

This report was prepared as an account of work sponsored by an agency of the United States government. Neither the United States government nor any agency thereof, nor any of their employees, makes any warranty, express or implied, or assumes any legal liability or responsibility for the accuracy, completeness, or usefulness of any information, apparatus, product, or process disclosed, or represents that its use would not infringe privately owned rights. Reference herein to any specific commercial product, process, or service by trade name, trademark, manufacturer, or otherwise does not necessarily constitute or imply its endorsement, recommendation, or favoring by the United States government or any agency thereof. The views and opinions of authors expressed herein do not necessarily state or reflect those of the United States government or any agency thereof.

Available to DOE and DOE contractors from:

Office of Scientific and Technical Information (OSTI)

P.O. Box 62

Oak Ridge, TN 37831

Prices available by calling 423-576-8401

Available to the public from:

National Technical Information Service (NTIS)

U.S. Department of Commerce

5285 Port Royal Road

Springfield, VA 22161

$703-605-6000$ or $800-553-6847$

or

DOE Information Bridge

http://www.doe.gov/bridge/home.html 


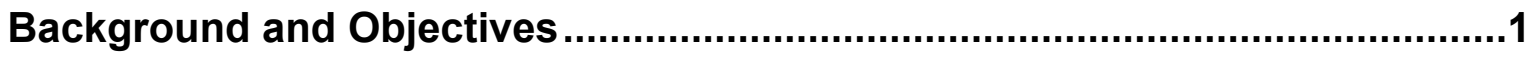

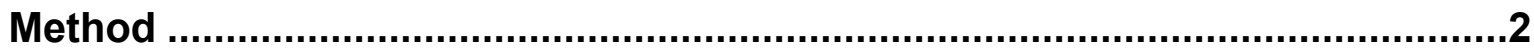

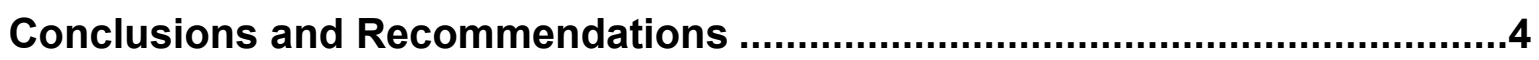

\section{Detailed Findings}

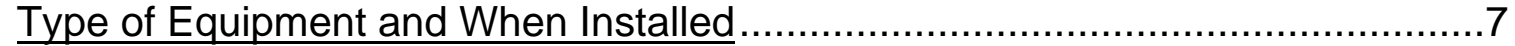

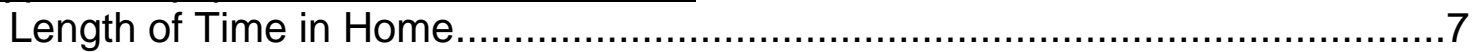

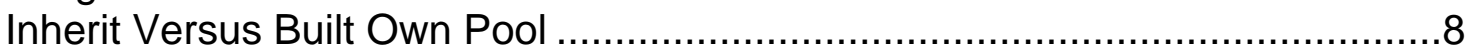

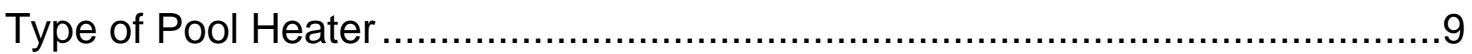

Effect of Pool on Home Purchase Decision ..............................................10

Effect of Pool Heating Costs on Home Purchase Decision..............................11

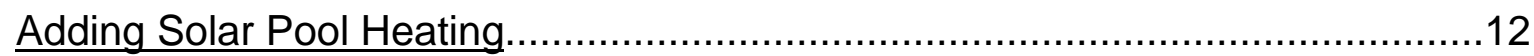

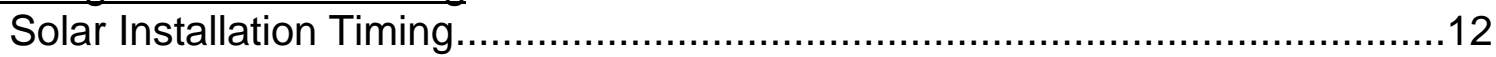

When Solar Heating was Added to the Pool ............................................13

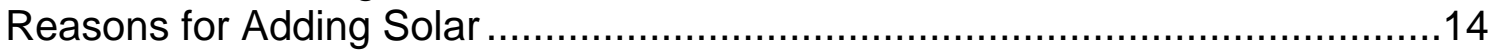

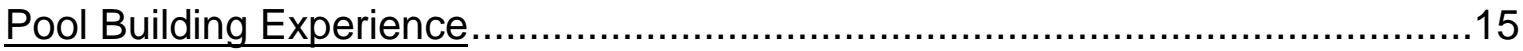

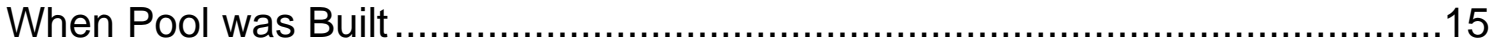

How Decide Upon Type of Pool Heater ......................................................16

Builder Discuss Pool Heating Costs.......................................................17

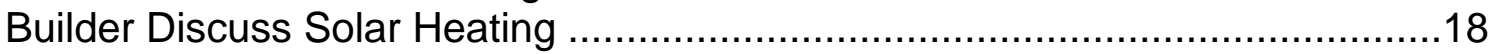

What Builder Said About Solar ...........................................................19

Likelihood of Installing Solar if Builder Recommended ................................19

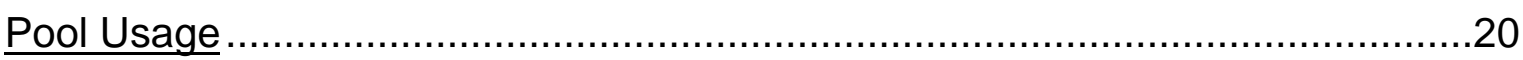

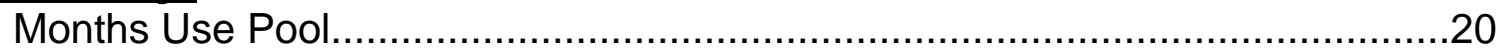

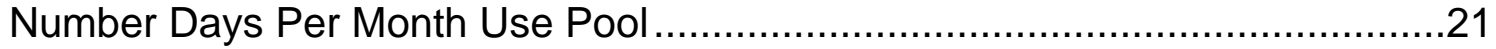

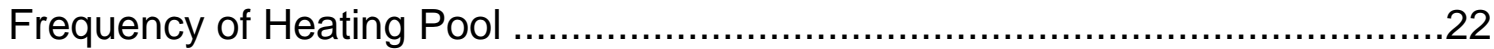

Change in Usage Based Upon Solar ......................................................23

Perceptions of Costs Associated with Pool Heating .........................................24

Cost to Heat Per Month During Primary Months ........................................24

Actual Costs Compared to Expectations.....................................................25

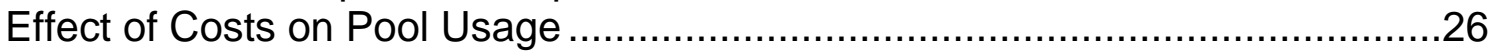

Use Pool More if Costs Less to Heat .......................................................27

Perceived/Actual Costs of Installing Solar .................................................28

Perceptions of Reasonable Price for Solar System ......................................29 


\section{TABLE OF CONTENTS (CONT'D)}

Attitudes and Awareness of Solar Pool Heating .............................................30

Source of Solar Pool Heating Awareness ..................................................... 30

Perceived Advantages of Solar Pool Heating ............................................

Perceived Disadvantages of Solar Pool Heating ........................................33

Purchase Interest in Solar Pool Heating ...............................................34

Non-Users Ever Consider Solar ......................................................... 34

Reasons for Not Selecting / Not Considering Solar ....................................

Type of Heater Most Likely to Install in New Home ......................................36

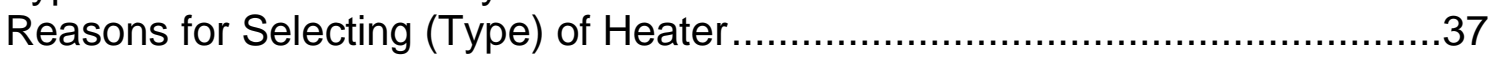

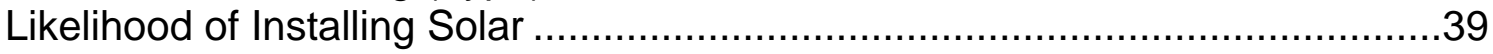

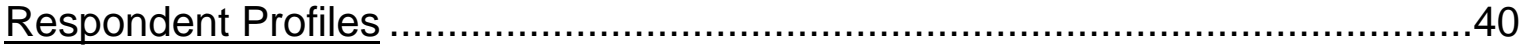

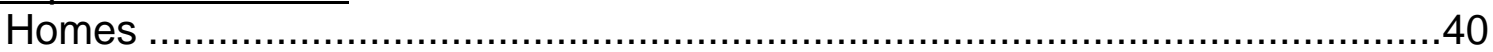

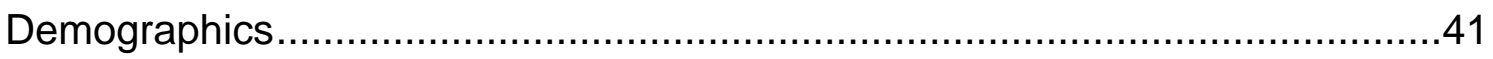

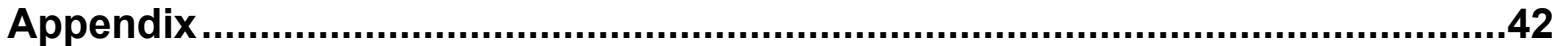

Questionnaire 
Solar swimming pool heating is an economical, environmentally correct heating method for pools throughout the United States. The first commercial manufacturer of solar pool heating products in the U.S. opened their doors in the early 1960's, and the business has grown steadily ever since. Today, four major manufacturers account for approximately $90 \%$ of the U.S. production, and annual domestic installations number approximately 25,000 systems, growing at a rate of $5 \%$ or less per year. The majority of these systems are installed in the sunbelt states, primarily in Florida and California. However, systems are installed on both in-ground and above-ground pools throughout the country. The above-ground market is probably the fastest growing segment today.

The vast majority of solar collectors used today are constructed from polymer materials, which have been shown to offer the best durability and reliability over the years. In fact, some systems installed 25 years ago or more are still in operation today.

Conventional swimming pool heaters consume vast amounts of energy, typically from natural gas, or in some areas, electric heat pumps or other fossil fuels. While the solar swimming pool manufacturing industry remains strong today, higher growth rates are desired to spur manufacturing jobs, reduce the production of greenhouse gases, and reduce the consumption of fossil fuels. Accordingly, the National Renewable Energy Laboratory (NREL) and the U.S. Department of Energy's Solar Buildings Program are working to develop effective strategies that will grow this industry.

To this end, a quantitative research study has been commissioned that involves gaining a better understanding of the marketplace from the perspective of residential pool owners. Specific objectives of this research are to:

- Gain an understanding of consumer awareness and images of solar pool heating systems.

- Quantify consumer interest in solar pool heating.

- Determine builder involvement and influences in pool heating selection.

- Identify the key motivators and barriers to purchase interest among pool owners.

- Determine the relative affluence of solar swimming pool heating system purchasers as compared with non-purchasers. 


\section{METHOD}

The method used for this quantitative research was as follows:

Who: In total, 454 interviews were completed. The breakdown of the sample is:

\begin{tabular}{lll} 
& \multicolumn{3}{c}{ Solar Users Solar Non-Users } \\
\cline { 2 - 3 } California & 79 & 75 \\
Arizona & 76 & 74 \\
Florida & $\underline{75}$ & $\underline{75}$ \\
Totals: & 230 & 224
\end{tabular}

The solar user sample consisted of names provided by representatives from the solar pool heating industry. Customer lists were provided, and calls were placed randomly across those lists. All solar users were screened for the following requirements:

- Own the home they are living in

- The home is a detached single family home

- Owned the home longer than one year (majority 1-5 years)

- Have a swimming pool that is heated by solar panels

The non-user sample was obtained by purchasing a lists of pool owners across the three specified states. Names were called randomly from these lists. All non-users were screened for the following requirements:

- Own the home they are living in

- The home is a detached single family home

- Owned the home 1-5 years

- Have a swimming pool that is NOT heated by solar panels

IMPORTANT NOTE ABOUT THE SAMPLE:

This study was designed to provide a sample size large enough among both solar users and non-users to be statistically reliable. With this in mind, it was agreed to split the sample in half. However, in the "real world," substantially fewer than half of all pool owners use solar heating equipment. Consequently, when looking at the figures provided in total, it is important to keep in mind that these numbers represent the total of those interviewed, and not what the total population in general would be like. 
What: Telephone interviews lasting approximately ten to twelve minutes each.

When: Interviewing was conducted from October $10^{\text {th }}$ to December $1^{\text {st }}, 1998$. There was a short break in interviewing during this period while more user sample was being obtained.

Question Areas: (See Appendix for questionnaire)

- Type of pool heating equipment and when installed

- Pool Usage

- Perceptions of costs associated with pool heating

- Attitudes toward solar pool heating

- Purchase interest in solar pool heating

- Demographic profiles

Statistical Testing:

Statistical testing was conducted across all subgroups analyzed. Throughout the report statistically significant differences are noted between subgroups at the $90 \%$ level of confidence. This means that if this study were replicated among the target sample, differences between the same subgroups would occur nine out of ten times tested. In other words, when significant differences exist, the attitudes, opinions and/or behavior being discussed is clearly different between the various groups being discussed, such as solar users versus non-users, or pool owners in California versus Arizona versus Florida.

Directional differences are noted where subgroups differ at the $80 \%$ level of confidence. While directional variations do indicate differences in opinions between subgroups, the differences are not as strong or as reliable as significant differences. Directional differences do provide good insights when coupled with common sense about the subject being discussed.

When differences between groups are not discussed, it may be assumed that no statistical differences exist between key subgroups. 


\section{CONCLUSIONS AND RECOMMENDATIONS}

\section{ConCLUSION 1:}

Solar users can generally be described as pool owners who wanted to be able to use their pools for a longer period of time without having to pay a fortune to do so. Saving money overall is viewed as an advantage as well.

- Seven in ten of the users surveyed installed their solar systems after their pools were already built.

- The reason given most often for adding solar pool heating is to be able to use the pool longer. Saving money represents a secondary factor in their decision to add solar pool heating.

- Once installed, solar users state that the key advantages to having solar pool heating are saving money and being able to use the pool longer.

\section{CONCLUSION 2:}

Solar users are extremely satisfied with their pool heating systems.

- Solar users do use their pools an average of two months longer throughout the year than do non-users. And eight in ten of these users keep their pools heated all of the time during the months they swim.

- Further, over eight in ten of those who added solar state that they use their pools more often than they did prior to having solar.

- Almost all of the solar users state that they would select a solar pool heating system again if they moved into a new home that needed a pool heater.

\section{CONCLUSION 3:}

Non-Users can be described as pool owners who do not place heating their pool high on their priority list, but may possibly be open to the idea of solar pool heating.

- Almost all of the non-users purchased homes that came with a pool, and three-fourths of these pools are not heated at all.

- While two-thirds of the non-users agree that the pool was a factor in their home purchase decision, only one in five feel that the pool heating cost was something they even considered in deciding on purchasing this home. This is probably related to the fact that if they do not heat the pool then the cost is a non-issue.

- The large majority of non-users have never considered installing a solar pool heating system, with the cost of installation and the lack of a perceived need being the key reasons they have not looked into this type of purchase.

- However, despite the fact that most of these non-users have not made heating their pools a priority, four in ten of them indicate that they would be likely to install a solar pool heater if moving to a new home that needed a heater. 


\section{Conclusion 4:}

Pool owners in California appear to be more consistent demographically with solar users, and they express greater interest in solar pool heating than do those in Arizona and Florida.

- Almost half of the non-users in California currently heat their pools, whereas very few non-users in Arizona and Florida ever heat their pools.

- The cost of pool heating was a factor in the home purchase decision among those in California significantly more often than among those in Arizona and Florida.

- While none of the non-users are realistic about what they feel a reasonable price would be for a solar pool heater, those in California come significantly closer to reality than do those in Arizona and Florida. This may also be related to the fact that non-users in California have higher incomes on average than those in Arizona and Florida.

\section{CONCLUSION 5:}

The cost of installation is clearly the primary barrier to purchasing a solar pool heater.

- Non-users feel that the cost of installing a solar pool heater outweighs the benefit of a longer swimming season. Specifically, while the cost of heating via gas or electricity is clearly more expensive, it is not more than is expected, and does not deter these pool owners from using their pools on a frequent basis.

- On average, non-users perceive the cost of installing a solar pool heater to be about $\$ 2,500$, but feel that a reasonable price would only be $\$ 1,400$ on average.

- When asked to name any disadvantages of solar pool heating, the number one response is that it is too expensive to install.

- When asked why those who considered solar decided against it, the number one response is because of the cost of installation. Similarly, many of those who have never considered solar pool heating have not considered it for the same reason.

\section{CONCLUSION 6:}

While those in the pool building industry do not appear to be greatly helping the solar pool heating industry, they do not appear to be consciously hurting it either.

- About half of those who built their pools indicated that their builder discussed heating costs with them. And most of those who discussed solar note that their builders said positive things about the money savings and longer swimming season offered by solar pool heating.

- About one-fifth of the users who built their pools chose solar based upon their builder's recommendation. 


\section{CONCLUSION 7:}

Solar users appear to be significantly older, more affluent and live in larger, more valuable homes than non-users. This is true more so among those in California and Arizona than among those in Florida.

- On average, solar users are significantly older than non-users - early fifties versus early forties on average. In terms of household incomes, solar users in California and Arizona have higher incomes on average than non-users, while incomes do not vary across these groups in Florida.

- Also, solar users in California and Arizona have larger homes on average in terms of square footage and home values than do the non-users in these states. While users in Florida report higher home values than do non-users, the home sizes are similar across users and non-users in Florida.

\section{RECOMMENDATIONS:}

The solar pool heating industry is doing a fantastic job of satisfying pool owners once they install the equipment. This level of satisfaction should be leveraged in all marketing, and/or public relations efforts.

The key to growth among non-users will be to position solar pool heating as something that will clearly add to their overall pool enjoyment. It will allow them to swim comfortably more often and for more months during the year, without stressing about the heating costs. These consumers must be convinced that the one time installation expense will clearly be worth the ongoing added enjoyment.

Obviously those who currently use pool heaters will understand the value of having a longer season in conjunction with saving money more easily than those who do not heat their pools. However, because the majority of non-users do not heat their pools, a monthly cost saving positioning alone offers no benefit to this larger group of pool owners.

While a substantial portion of non-users indicate an interest in purchasing a solar pool heater in the future, their perceptions of the installation costs are not at all realistic.

Consequently, the manner in which the installation costs are presented will need to be approached carefully. Clearly, the higher the income, the higher the likelihood of having several thousand dollars to spend on this type of "luxury" item.

For the most part, builders who do mention solar pool heating say positive things, but it appears that they do not present solar as a heating option on a consistent basis. The solar pool heating industry should continue to develop positive relationships with builders in order to make their products more top-of-mind. The industry should provide brochures and satisfied customer endorsements to builders on an ongoing basis to always maintain and refresh relationships with pool builders. 
As designed in this study, the majority of respondents have lived in their current homes between one and five years.

The large majority of the solar non-users purchased homes that came with the pool, and they do not heat their pools at all. As a result, the existence of a swimming pool was a factor in their home purchase decision, but the cost of heating the pool was not a purchase factor among most of these non-users.

About half of the solar users built their pools, while half inherited them.

\section{LENGTH OF TIME IN HOME}

Based upon the experience of the solar industry, this study primarily focuses on those who have owned their pool five years or less, since interest in heating a non-heated pool typically declines after that point. Consequently, all non-users were screened to have purchased or built their pool within the past five years. While the majority of the solar users interviewed (66\%) also have moved into their homes within the past five years, one-third have lived in their homes longer than this.

\section{Length of Home Ownership}

(Among Users: 230)

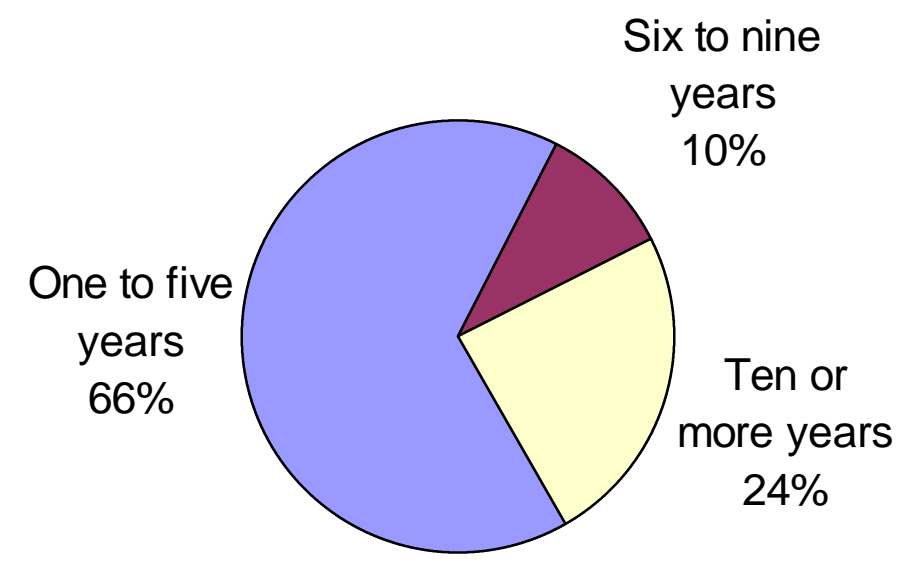

Q. D: How long have you owned this home? 


\section{INHERIT VERSUS BUILT OWN POOL}

About half of these users (51\%) built their own pools and chose to install solar pool heaters. Conversely, almost all of the non-users (93\%) inherited their pools which were not equipped with solar heaters. Only a small portion of non-users (7\%) built their pools and chose not to install solar.

\section{Inherit Versus Built Pool}

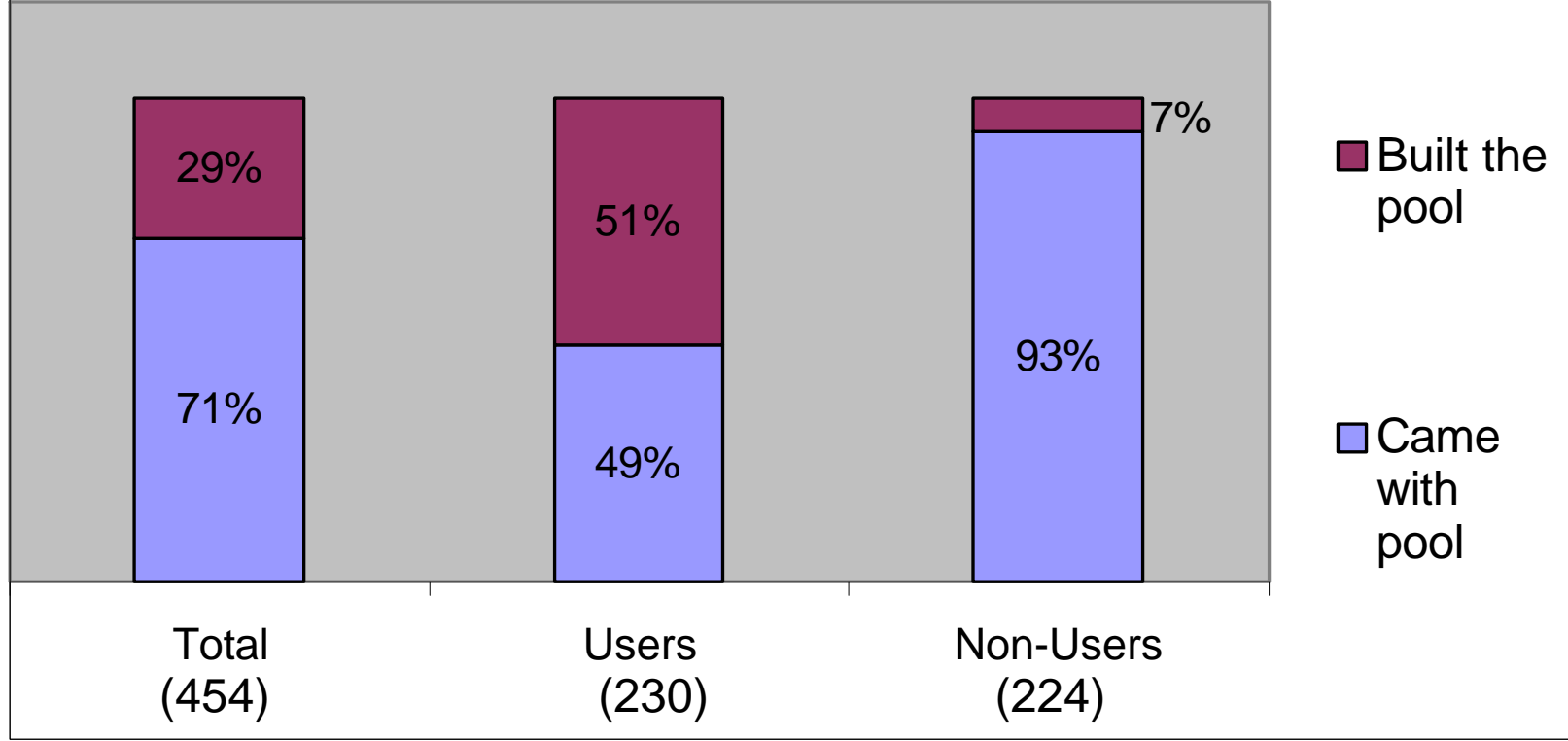




\section{TYPE OF POOL HEATER}

Over three-fourths (76\%) of the solar non-users interviewed do not use any type of heating system on their swimming pools at all. Just over one in ten (13\%) use natural gas, one in twenty (6\%) use an electric heat pump and another one in twenty $(5 \%)$ use a pool blanket or cover.

While the majority of solar non-users in each state do not heat their pools, a significantly larger portion of non-users in California use some other type of heater, mostly natural gas heaters or pool blankets, than do those in Arizona and in Florida.

\section{Type of Pool Heater}

(Among Non-Users: 224)

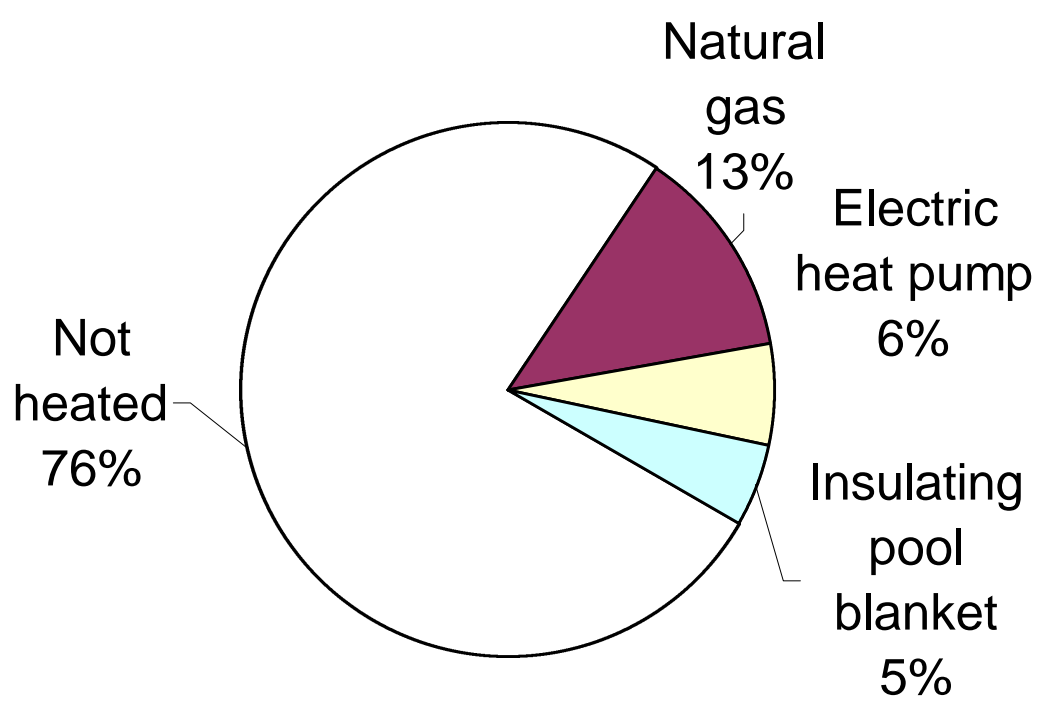

Q. F: What is the type of heating system that you use to heat the water in your pool? 


\section{EFFECT OF POOL ON HOME PURCHASE DECISION}

Among these non-users, the majority indicate that the existence of a swimming pool was a factor in their home purchase decision. This may in part explain why almost all of these non-users purchased homes that already had pools included.

\section{Pool A Home Purchase Factor \\ (Non-Users \& Pool came with Home: 208)}

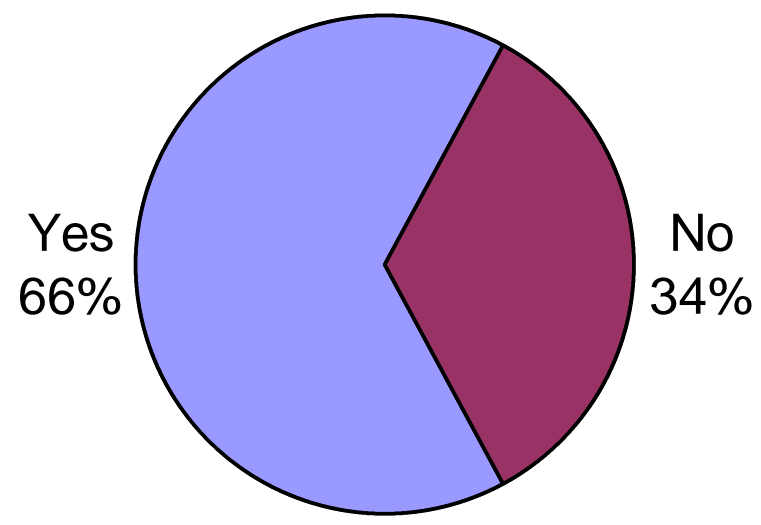




\section{EFFECT OF PoOl HeAting COSTS ON Home PuRCHASE DECISION}

Only about one in five (21\%) of the non-users who inherited their pools agree that the cost of heating the pool was a consideration when deciding whether to purchase their home.

Three-fourths $(77 \%)$ of these non-users who inherited their pools state that the cost of heating the pool was not a consideration when purchasing their home. This may be due to the fact that many of these respondents do not heat their pools at all.

The pool heating costs are more of a factor to those in California, where a larger portion actually heat their pools, than to those in Arizona and Florida. Specifically, Three in ten in California (32\%) feel this was a purchase factor to them versus two in ten in Arizona $(23 \%)$ and one in ten in Florida (9\%).

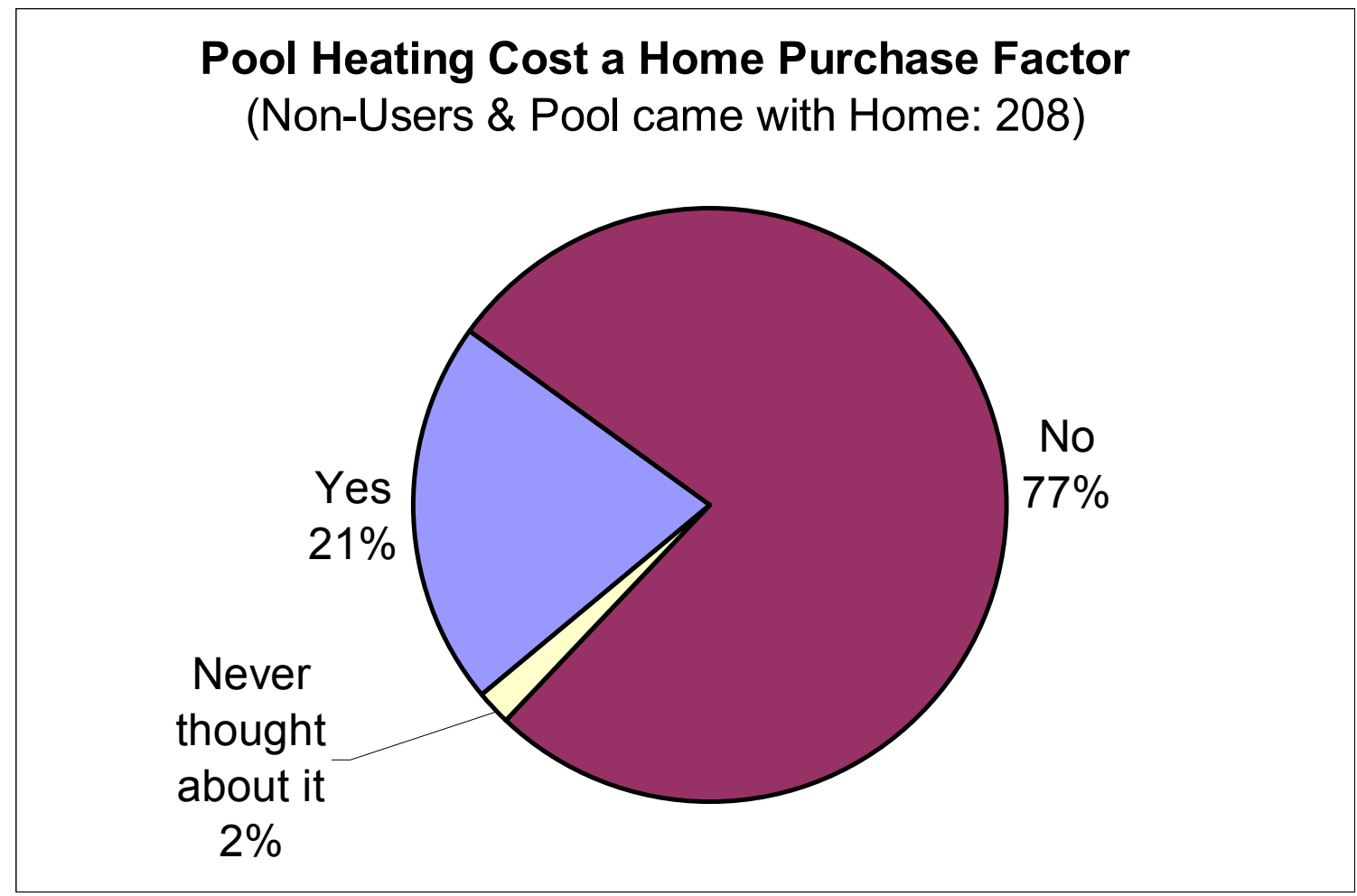

\begin{tabular}{|lrrr|}
\hline & CA & AZ & FL \\
& $(75)$ & $(74)$ & $(75)$ \\
Yes & $32 \%$ & $23 \%$ & $9 \%$ \\
No & $67 \%$ & $76 \%$ & $87 \%$ \\
Not thought & $1 \%$ & $1 \%$ & $4 \%$ \\
\hline
\end{tabular}

Q.4: When you purchased your home, did you consider the cost of heating the pool? 
The majority of these solar users added their pool heating systems within the past one to two years, after their pools were built. The primary reason for adding solar pool heating among these users was to extend their swimming season.

\section{WHETHER SOLAR WAS INSTALLED WHEN POOL WAS BUILT VERSUS ADDED LATER}

Not all solar users were committed to their solar pool heaters from the beginning of their pool plans. While half of the solar users did build their pools, only three in ten (28\%) indicate that their systems were installed during construction of the pool. Instead, seven in ten $(70 \%)$ indicate that their solar pool heating systems were added later. A significantly greater portion of those in California installed their solar systems when their pool was built versus those in Arizona and Florida, who more often added their systems later.

\section{Solar Installation Timing}

(Users: 230)

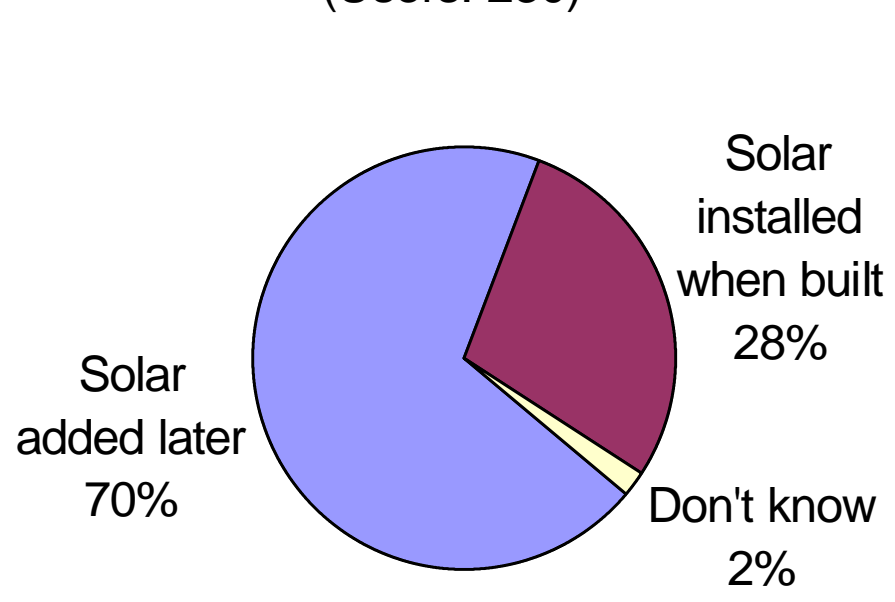

\begin{tabular}{|lrrr|}
\hline & CA & AZ & FL \\
& $(79)$ & $(76)$ & $(75)$ \\
Added later & $57 \%$ & $82 \%$ & $72 \%$ \\
Installed when built & $38 \%$ & $17 \%$ & $28 \%$ \\
Don't know & $5 \%$ & $1 \%$ & - \\
\hline
\end{tabular}

Q. 3: Was your solar pool heating system installed when the pool was built, or was it added later? 


\section{When SOLAR HEATING WAS Added to the PoOL}

Almost two-thirds (65\%) of those who added solar heating to their pools did so within the past one to two years, and about another third (29\%) did so three to five years ago.

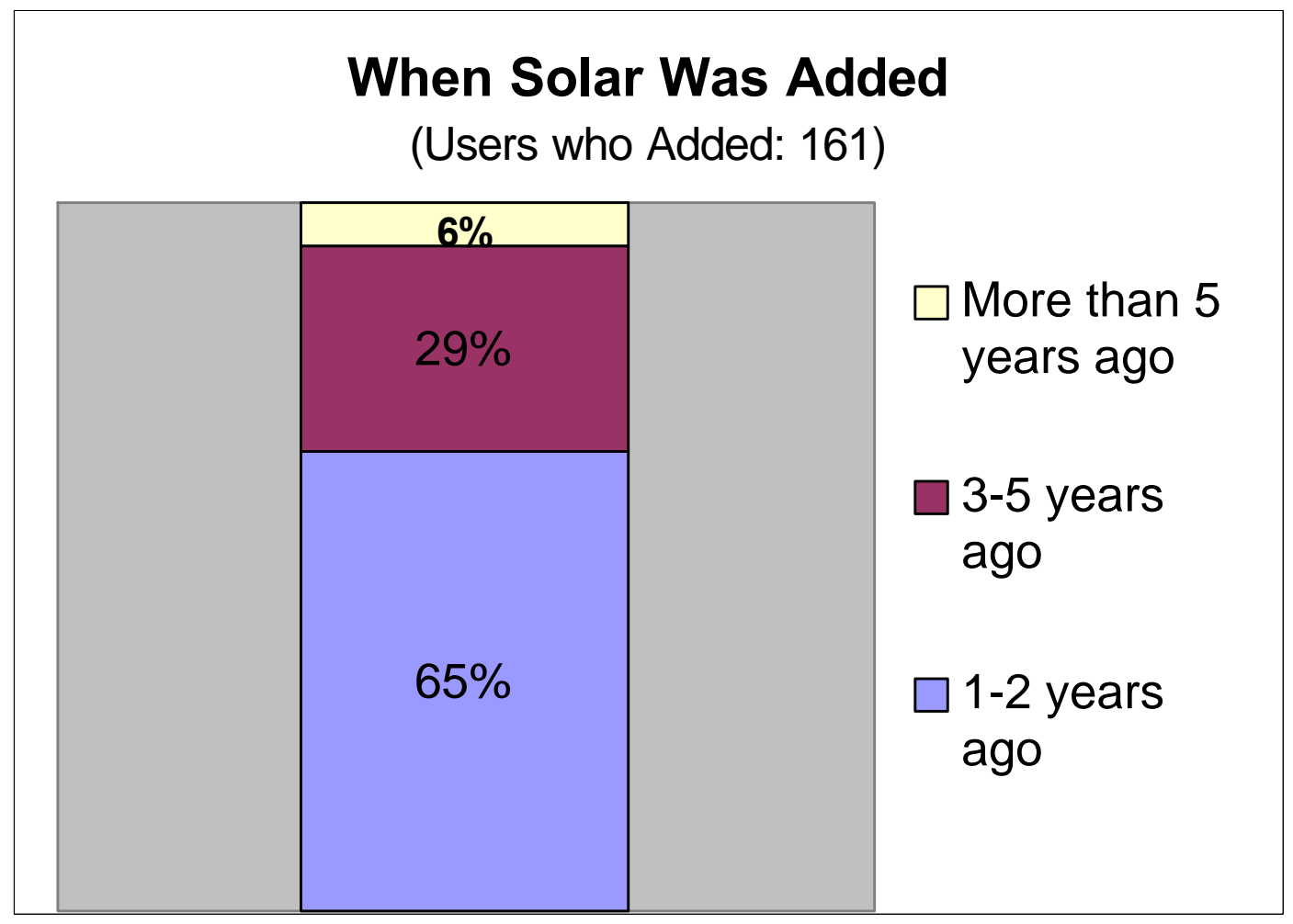

Q. 5: How many years ago did you add your solar pool heating system? 


\section{REASONS FOR ADDING SOLAR}

The primary reason for adding solar pool heating among those who did so was to extend their swimming season (40\%).

Just over one in ten note reasons for adding solar such as saving money (15\%), the old one costing too much (12\%), and the water was too cold/not heated well $(11 \%)$.

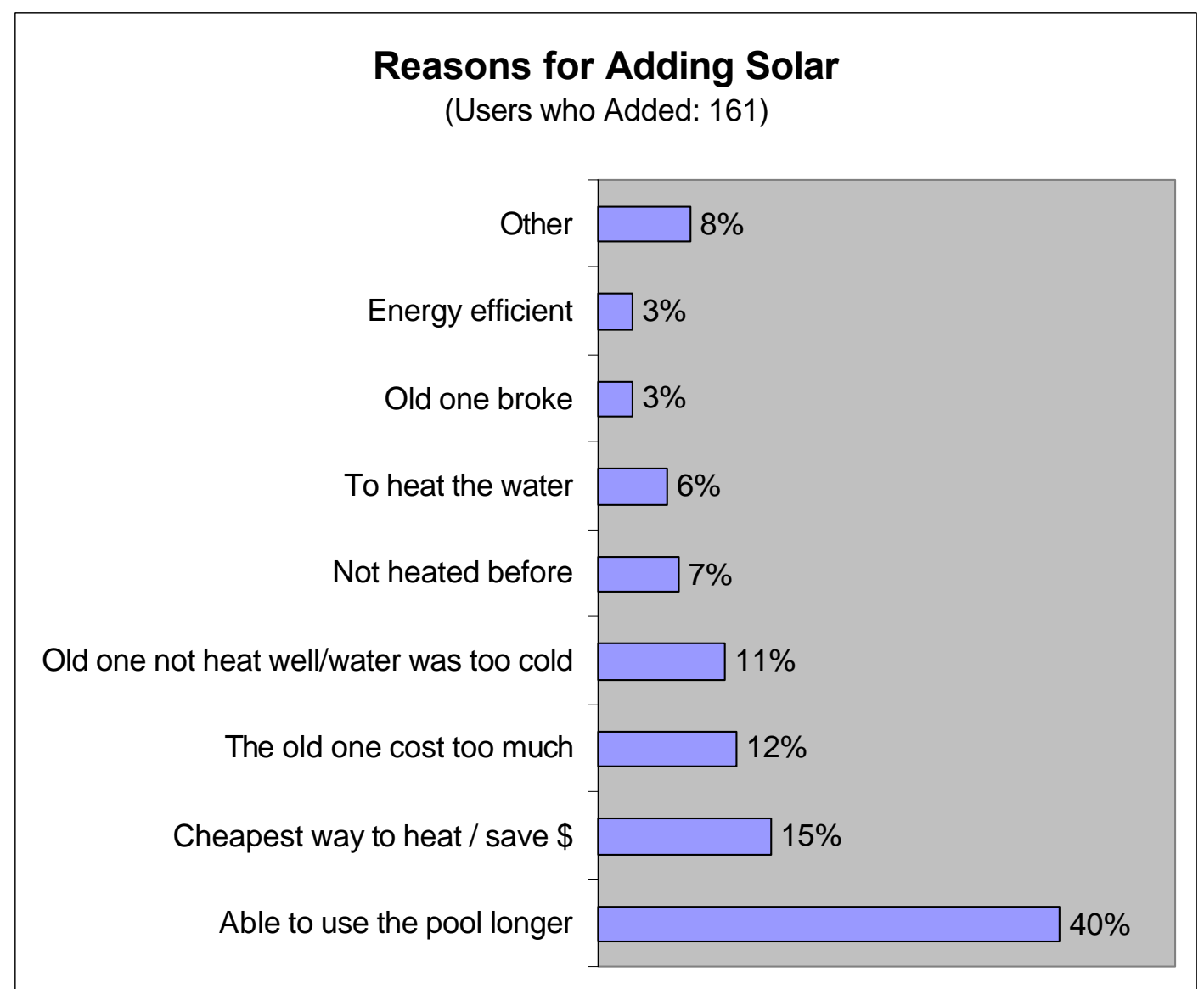

Q.6: Why did you have a solar pool heating system installed? 
Most of these respondents built their pools several years ago, and decided on the method of heating based upon the recommendation of their builder, their friends' recommendation, or a variety of other factors. It is difficult to draw conclusions about the pool heating decision among non-users, because so few built their own pools, and most of those who did chose not to install heaters.

Over four in ten of those who built did discuss the cost of heating their new pool with their builder, and just under four in ten discussed solar heating with them. The builder comments to these home owners were mostly favorable, mixed with some neutral comments. Very few builders made overtly negative comments about solar pool heating to these respondents who built their pools.

\section{WHEN POOL WAS BUILT}

Among those who built their pools, four in ten users and three in ten non-users built their pools within the past one to two years.

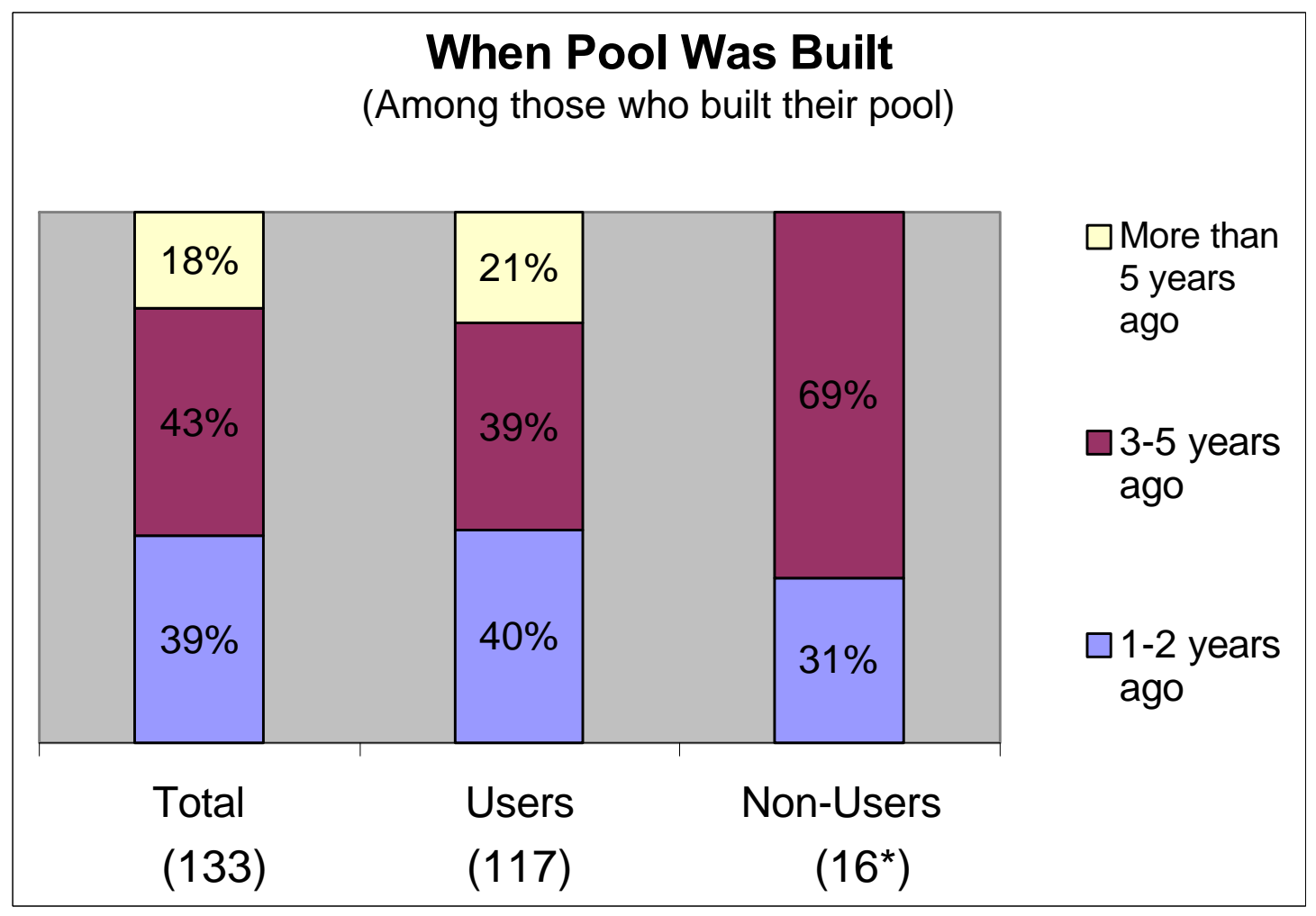

*Note: The non-User sample base is very small, and not statistically stable. Q.15: How many years ago did you build your pool? 
HOW DECIDE UPON TYPE OF POOL HEATER

Among respondents who built their pools, just under one in five respondents chose their method of pool heating based upon the recommendation of their builder $(18 \%)$ and/or a friend (17\%).

Interestingly, almost one in ten of the solar users (9\%) indicate that their builder chose the heating type for them.

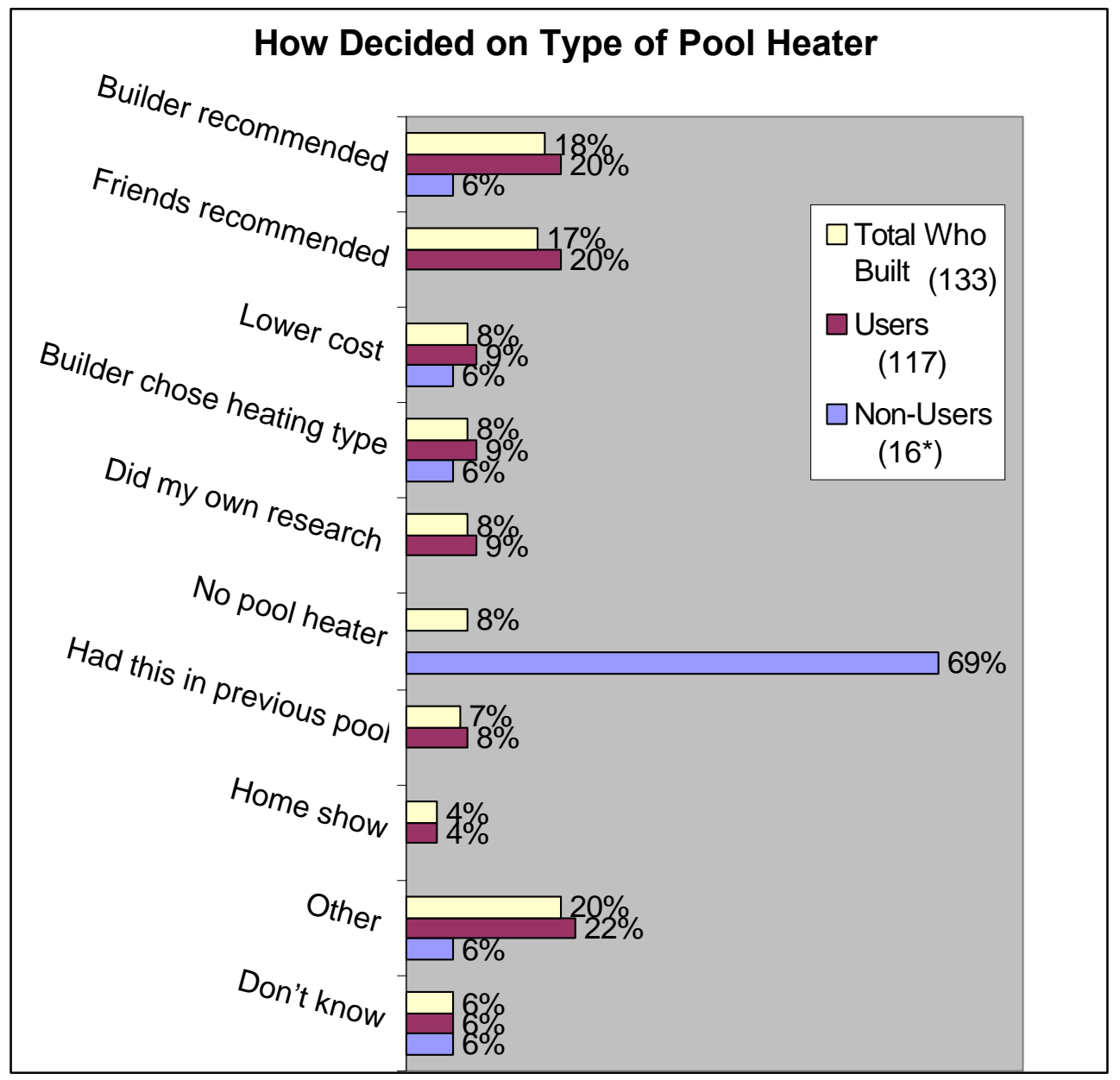

*Note: The Non-User sample base is very small, and not statistically stable.

Q.16: When you built this pool, how did you decide which type of heating to install? 


\section{BUILDER DISCUSS POOL HEATING COSTS}

Among those who built their own pools, about half discussed the cost of heating the pool with their builders, and about half did not (46\% versus $47 \%$ respectively).

Builders in Arizona discussed the costs of pool heating with these customers significantly less often than did builders in California and Florida.

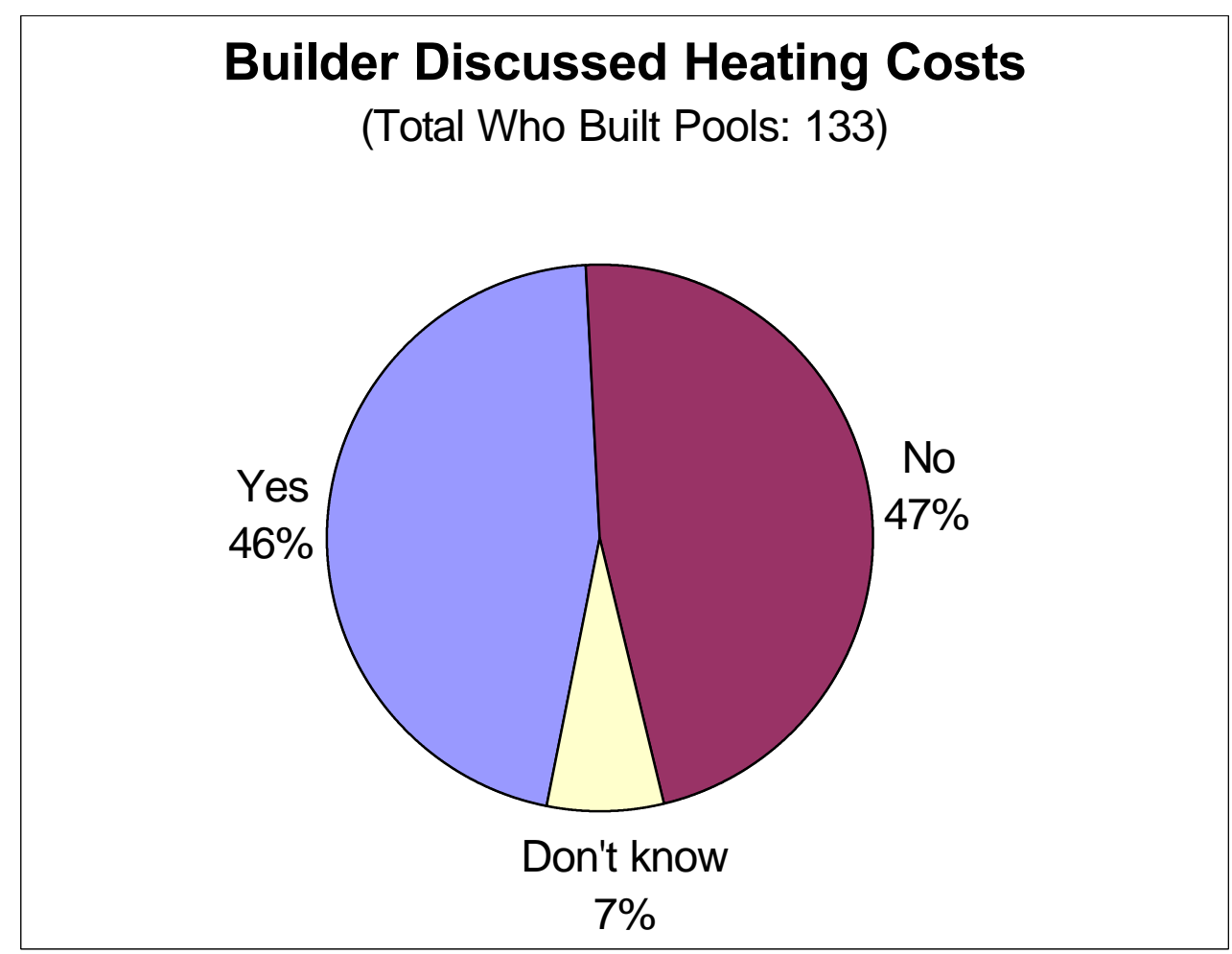

*Note: The sample base across individual states is very small, and not statistically stable.

Q.17: When you were planning your pool purchase, did the pool builder discuss the cost of heating your new pool with you? 


\section{BUILDER DISCUSS SOLAR HEATING}

Keeping in mind that the majority of the respondents in this study who built their own pools fall into the solar user group, only four in ten of those who built indicate that their builder discussed solar heating with them. Because significantly fewer of the builders in Arizona versus California and Florida even discussed heating costs with these consumers who built pools, significantly fewer discussed solar heating as well.

Interestingly, while only a small number of these non-users actually built their pool, six out of the sixteen non-users who built said that their builders did discuss solar with them.

\section{Builder Discussed Solar Heating}

(Total Who Built Pools: 133)

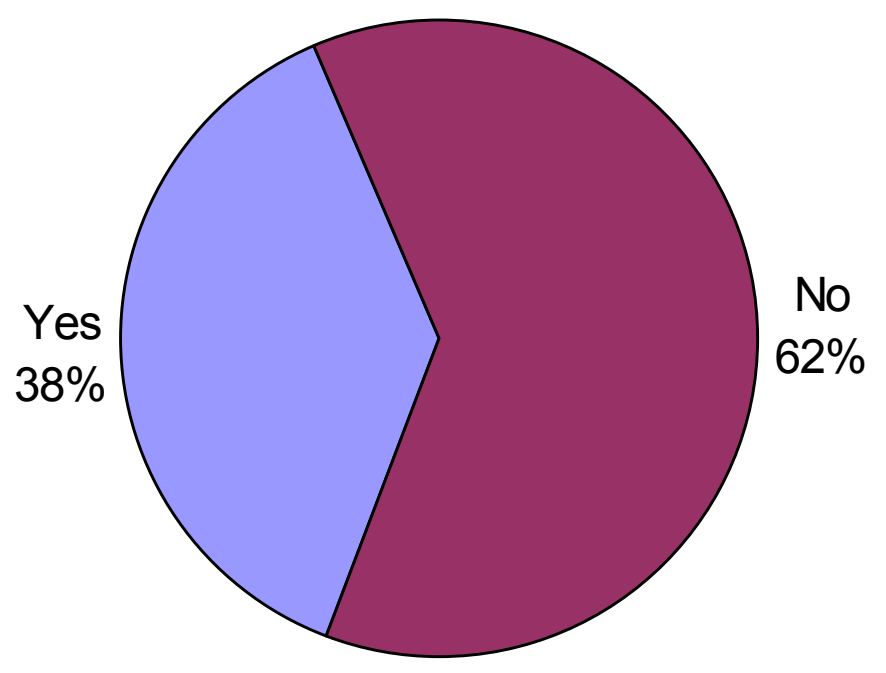

\begin{tabular}{|llll|}
\hline & CA & AZ & FL \\
& $\left(50^{*}\right)$ & $\left(42^{*}\right)$ & $\left(41^{*}\right)$ \\
Yes & $50 \%$ & $17 \%$ & $46 \%$ \\
No & $50 \%$ & $83 \%$ & $54 \%$ \\
\hline
\end{tabular}

*Note: The sample base across individual states is very small, and not statistically stable.

Q.18: Did your builder discuss solar heating with you? 


\section{WHAT BUILDER SAID ABOUT SOLAR}

Among the respondents who did discuss solar pool heating with their builders, the majority of builders offered positive comments $(65 \%)$, with most of the positive comments focusing on the economical advantages (47\%).

Fewer than one in ten (8\%) who discussed solar with their builder recall them saying something negative about solar pool heating.

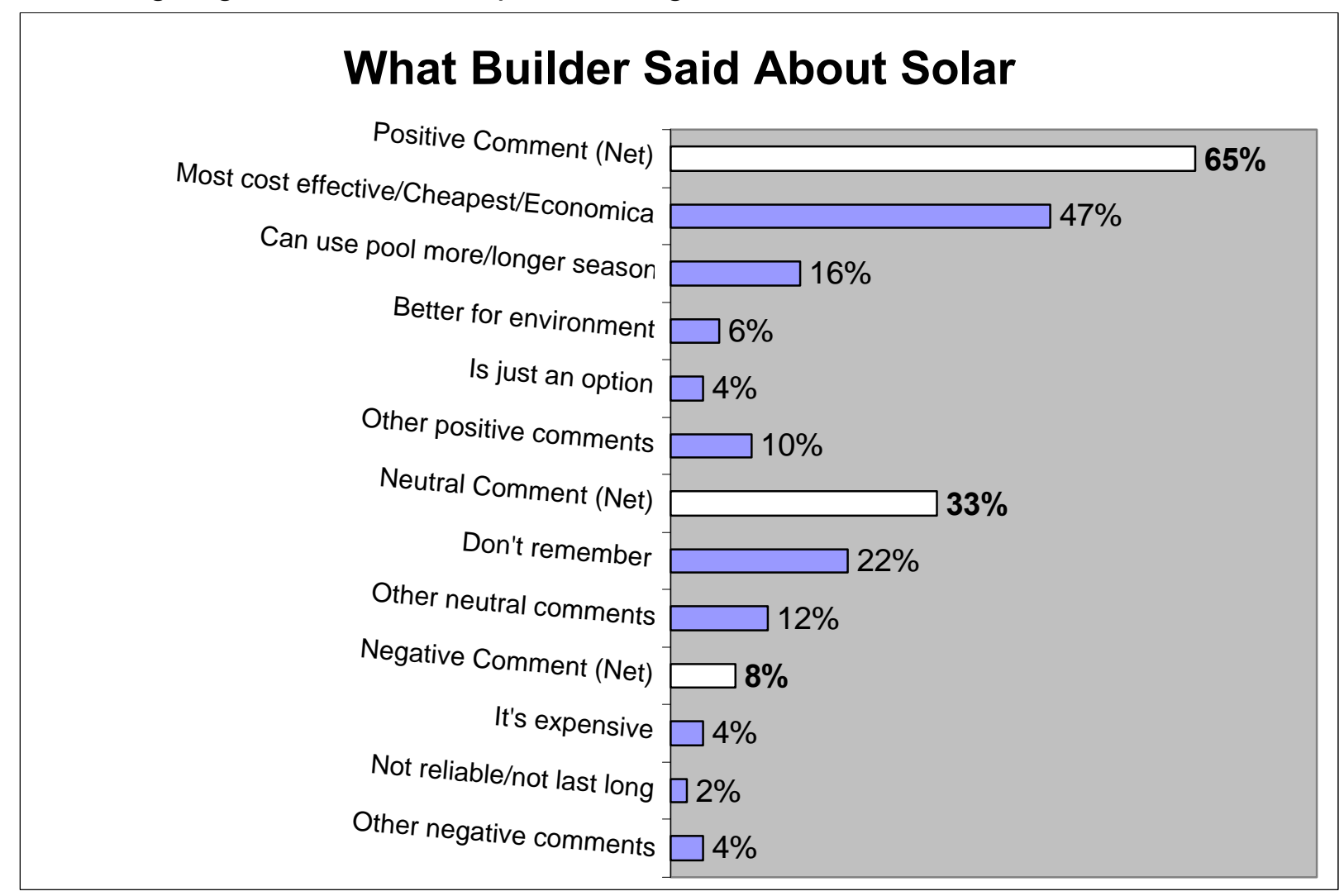

Q.19: What did your builder tell you about solar pool heating?

\section{LIKELIHOOD OF INSTALLING SOLAR IF BUILDER RECOMMENDED}

Among the ten non-users who built their pool and did not discuss solar pool heating with their builder, eight of them state that they probably would not have considered installing solar, even if their builder had recommended it to them.

Q.20: How likely would you have been to install a solar pool heating system if your builder had recommended it to you? 
Solar users do enjoy a longer swimming season than do non-users. However, the solar users only use their pools slightly more frequently than do non-users during the months the pools are used.

While most of these non-users do not heat their pools, solar users are significantly more likely to heat their pools than are the non-users who do have heating equipment. And those who added solar pool heaters note that they use their pools a lot more often with the addition of this equipment.

\section{MONTHS USE POOL}

With the exception of the summer months (June - August), a significantly larger portion of the solar users actually use their pools throughout the year than do non-users. This may be due to the fact that the majority of non-users do not heat their pools at all.

As a result, the majority of solar users actually use their pools from April through October, whereas a majority of non-users only use their pools during a shorter season; May through September.

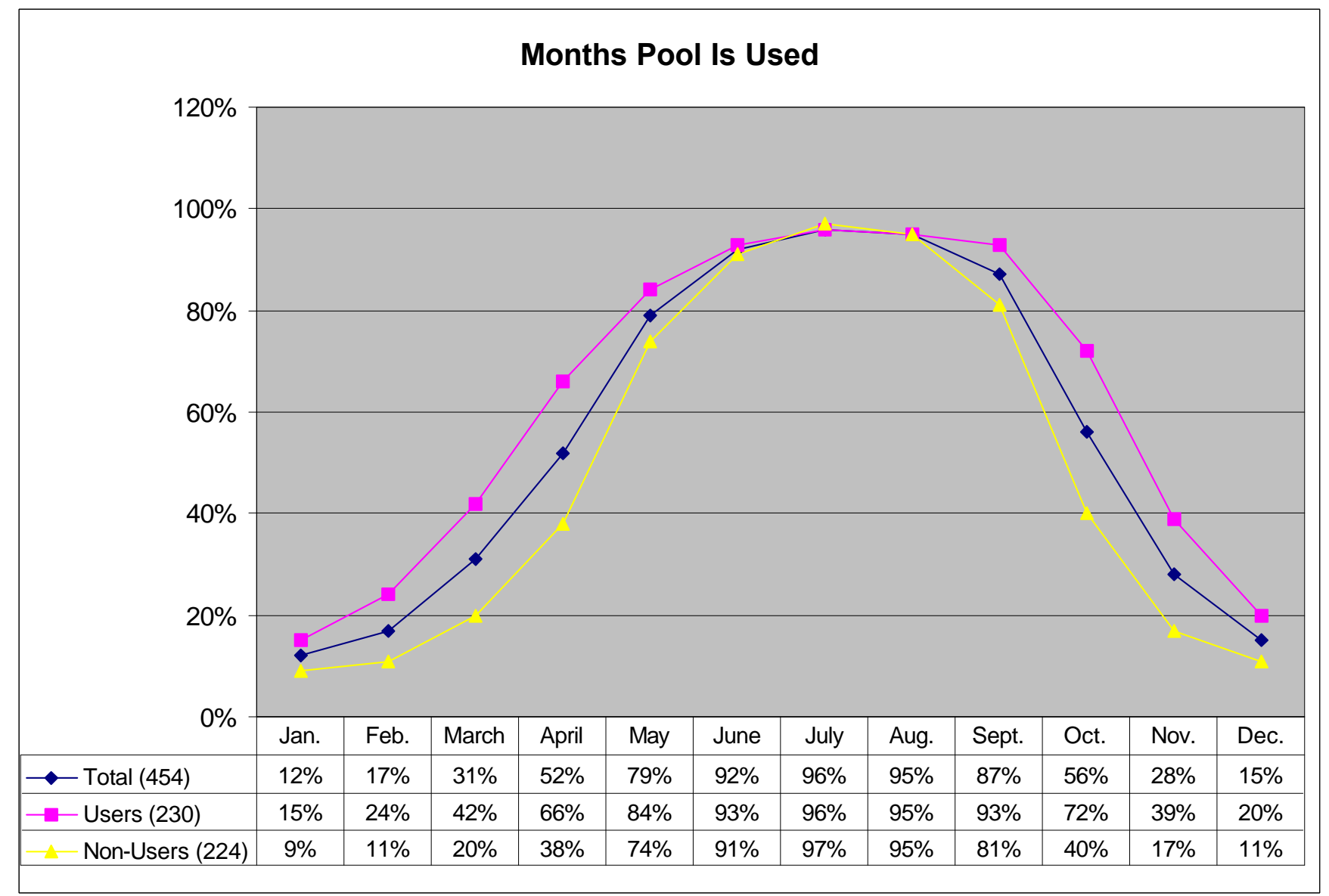

Q.8: In which months do you or your family members use your pool? 
NUMBER DAYS PER MONTH USE POOL

During the primary months that pool owners are swimming, their pools are being used an average of sixteen to seventeen days per month. This is true among both solar users and non-users.

In fact, about one-fourth (24\%) of these respondents use their pools almost every day during the key swimming months.

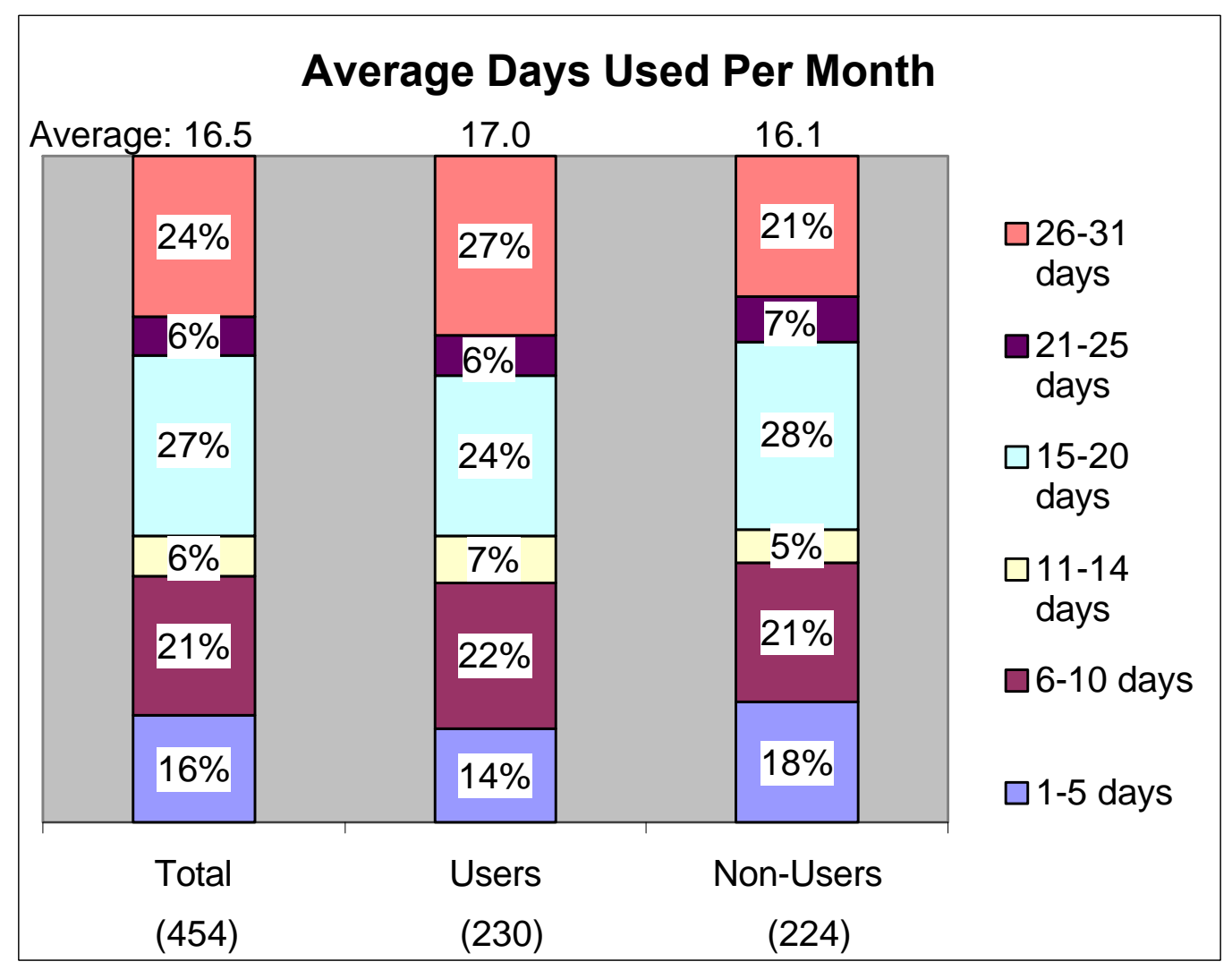

Q.9: During these months, how many days a month do you or a family member use the pool on average? 


\section{FREQUENCY OF HEATING POOL}

Solar users are significantly more likely to heat their pools than are the non-users who have heating equipment. Specifically, about eight in ten (79\%) of the solar users heat their pools all of the time, whereas four in ten $(40 \%)$ of the non-users who have alternate equipment never even use it.

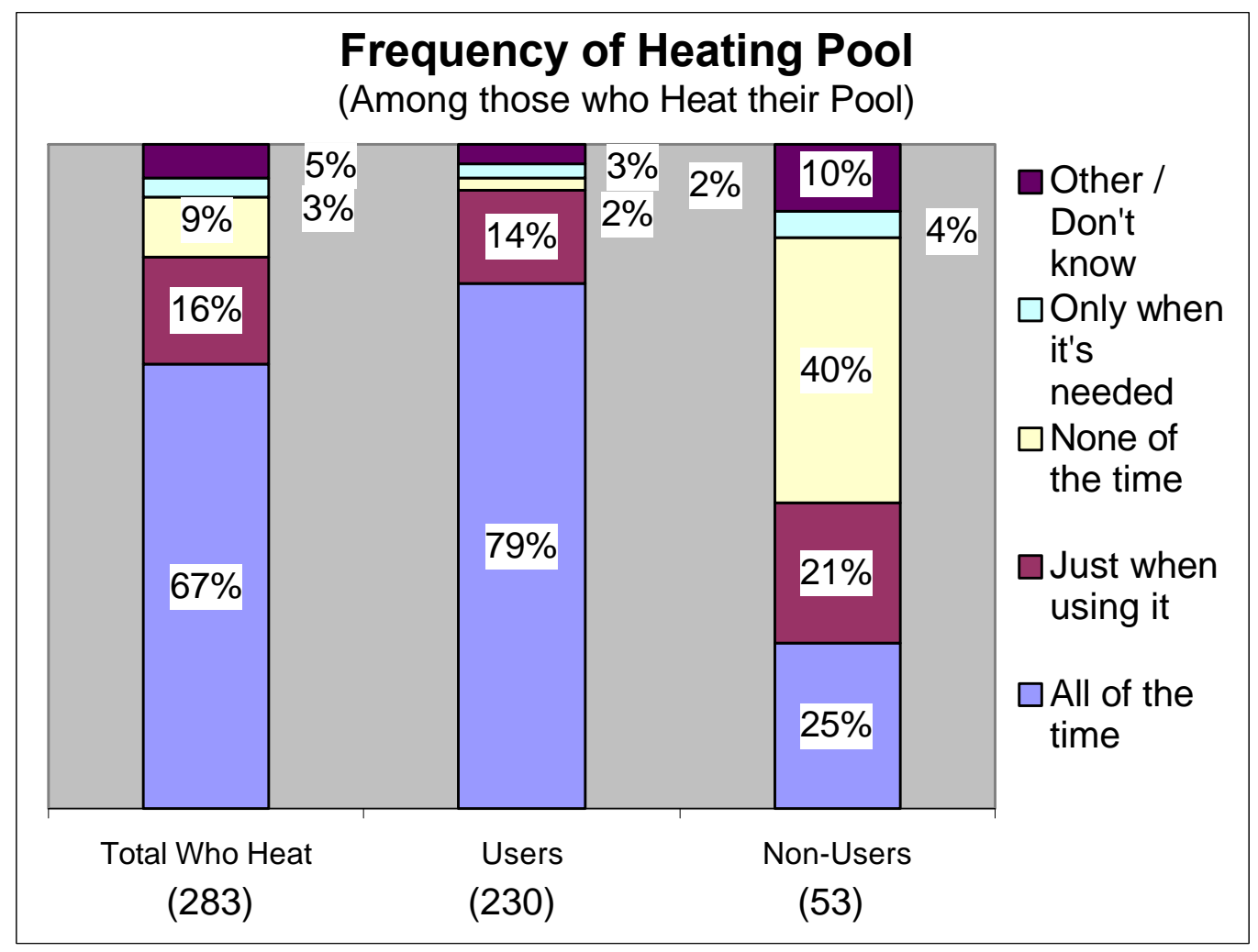

Q.10: During the months that you use your pool, do you keep your pool heated all of the time, just on days when you are using it, or none of the time? 


\section{CHANGE IN USAGE BASED UPON SOLAR}

The addition of solar pool heating equipment clearly has a positive effect on pool usage. Over half (55\%) of those who added solar use their pools a lot more often than before, with another fourth $(26 \%)$ using their pools a little more than before. This is especially true among solar users in Florida, who increase their pool usage "a lot more" significantly more than do those in California and Arizona.

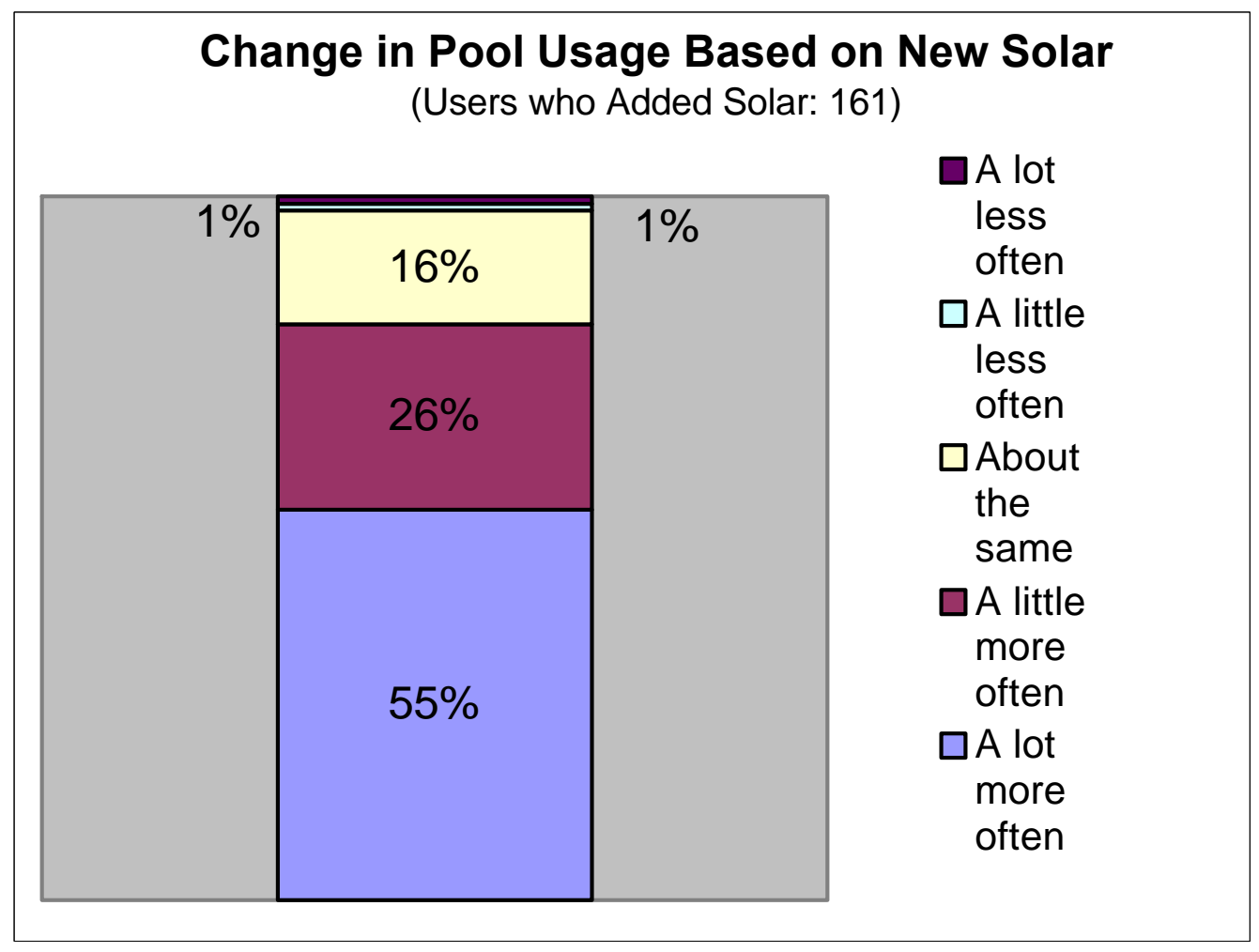

*Note: The sample base across individual states is very small, and not statistically stable. Q.7: Now that you have a new pool heating system, do you find that you use your pool...? 
While non-users who heat spend significantly more on pool heating than solar users spend, very few feel the costs are more than they expected. However, about one-third of these non-users admit that these heating costs deter them from swimming either frequently or occasionally. And over four in ten of these non-users who heat feel they would use their pools more if it cost less to heat.

While non-users show signs of interest in solar pool heating, they are quite unrealistic about what it will take to have a solar pool heating system. Specifically, solar users indicate they spent an average of $\$ 3,351$ for their systems. While non-users think it would cost them $\$ 2,519$ for a solar pool heater, they think that a reasonable price would only be $\$ 1,388$. And many non-users simply have no idea what it would cost for a solar pool heating system.

\section{Cost to Heat Per Month During Primary Months}

Not surprisingly, those who heat their pools with solar energy spend significantly less per month on their heating bills than do those with other types of heaters. On average, those who heat their pools with solar energy spend about $\$ 18.50$ per month during the primary swimming months. While more than half $(52 \%)$ of the non-users who heat their pools do not know what they spend to do so, non-users who know spend an average of $\$ 55.20$ per month to heat their pools during these primary months.

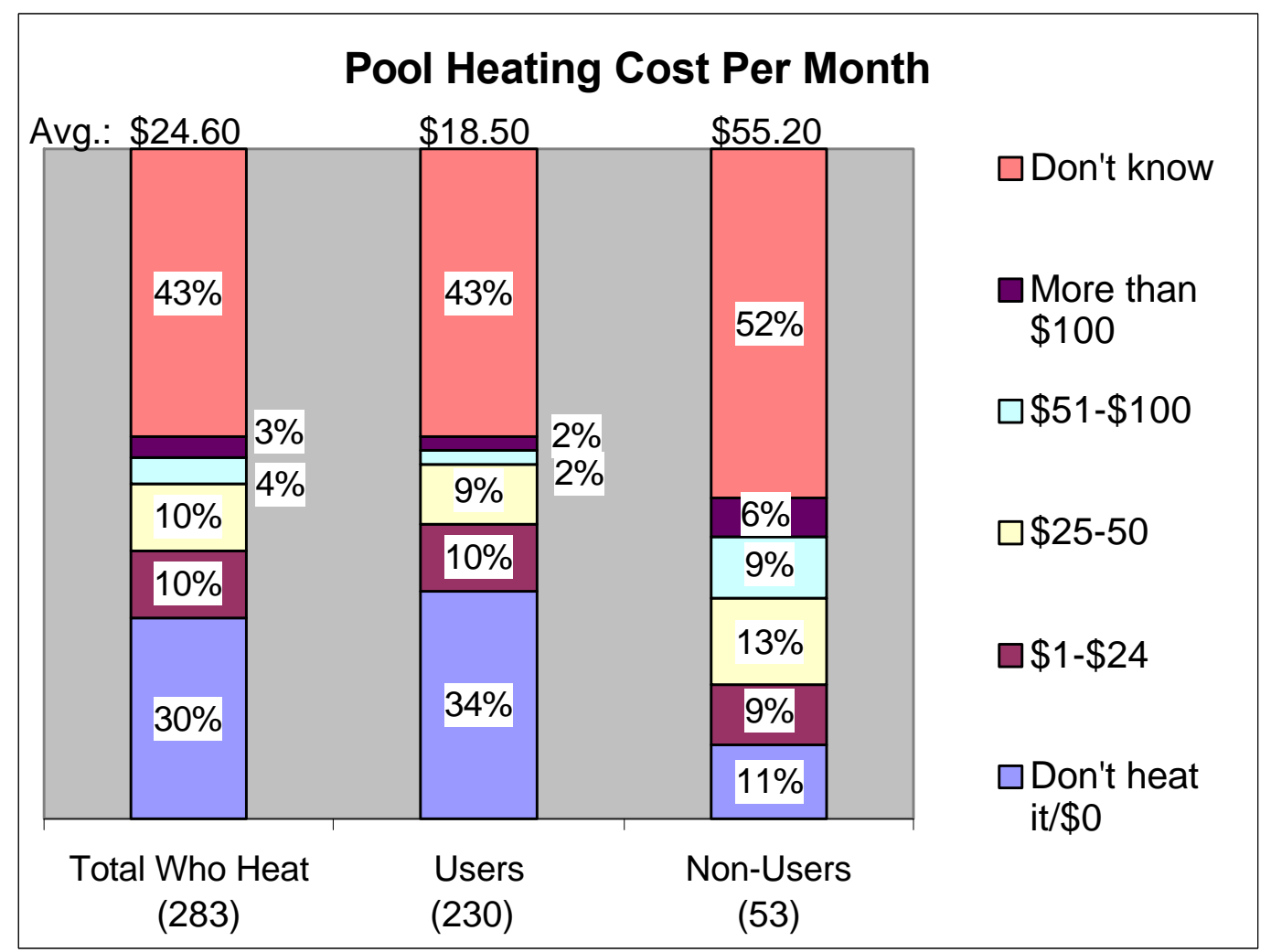

Q.11: Now that you've owned your pool for some time, how much do you believe it costs per month to heat your pool during the primary months you use it? 


\section{ACTUAL COSTS COMPARED TO EXPECTATIONS}

While non-users spend significantly more on their pool heating bills than do solar users, almost half (45\%) acknowledge that their bills are about what they expected. Only one in ten non-users who heat their pool $(9 \%)$ feel that their heating bills were more that they expected. Conversely, almost none of the solar users (2\%) indicate that their solar bills are higher than expected.

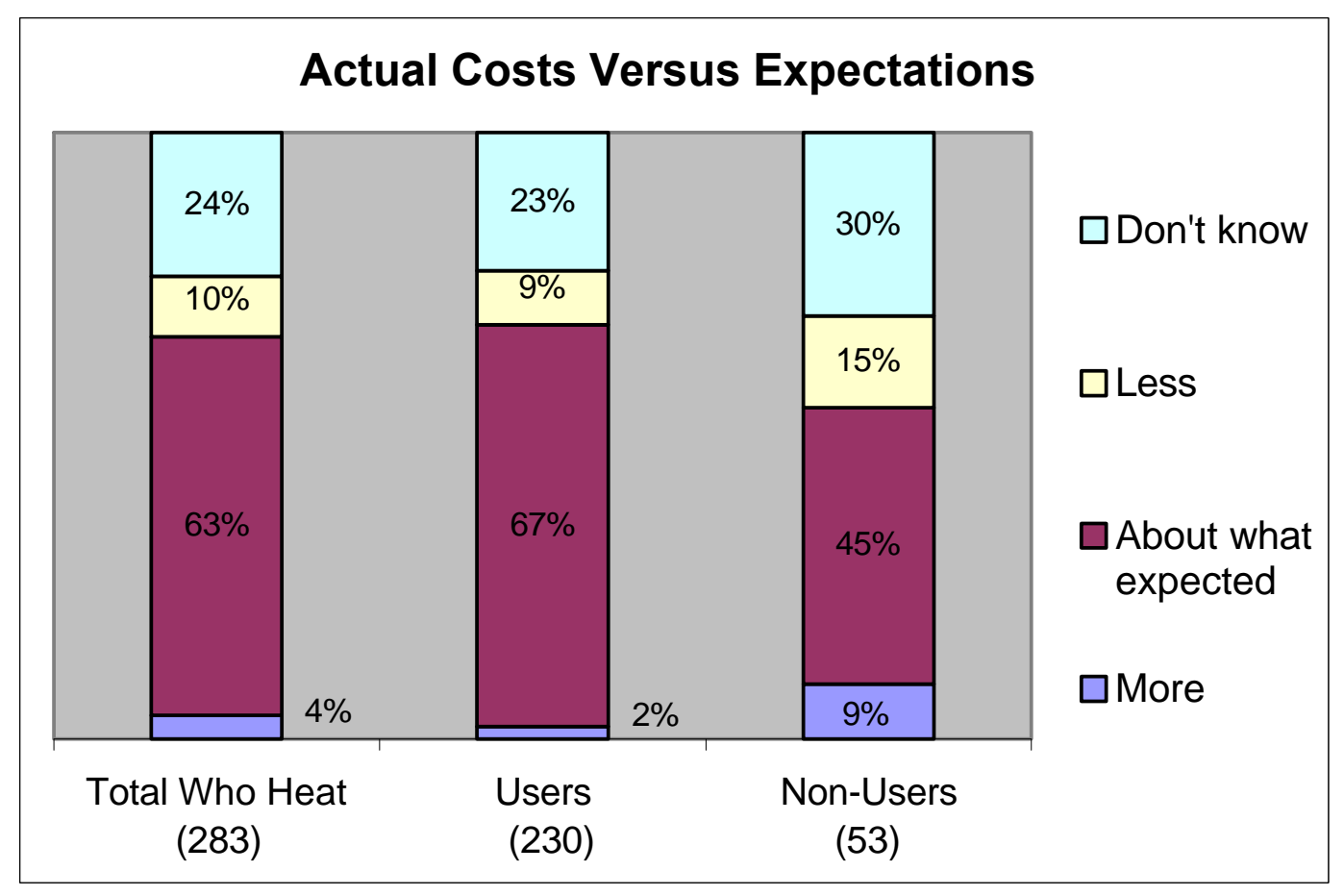

Q. 12: Is this amount more, less, or about what you expected it would be? 


\section{EFFECT OF COSTS ON POOL USAGE}

While few non-users feel that their pool heating bills are more than expected, about one-third $(32 \%)$ of the non-users who heat their pools feel the costs of doing so deter them from using their pools either frequently or occasionally.

Surprisingly, a small portion of solar users indicate that the cost of heating their pools deters them from swimming.

As expected, non-users are deterred from swimming due to the cost of heating significantly more often than solar users, (32\% versus $14 \%$ deterred frequently/occasionally).

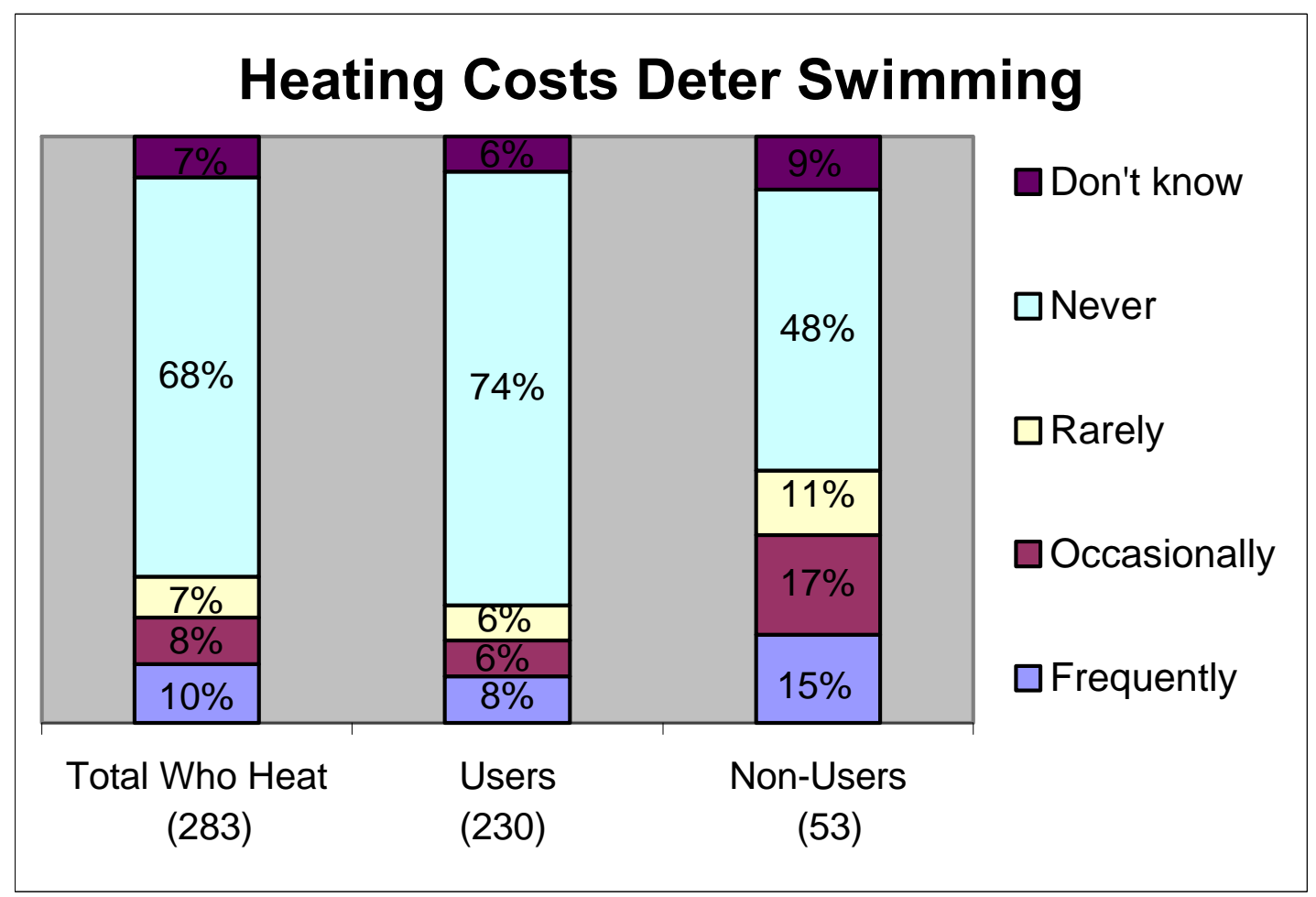

Q.13: Would you say the cost of heating your pool causes you to choose not to go swimming in your pool frequently, occasionally, rarely or never? 


\section{USE POOL MORE IF COSTS LESS TO HEAT}

Over four in ten (43\%) of the non-users who heat their pool do admit that they would be likely to use their pool more often if it cost less to heat.

\section{Likelihood of Swimming More if Heating Cost Less (Non-Users Who Heat: 53)}

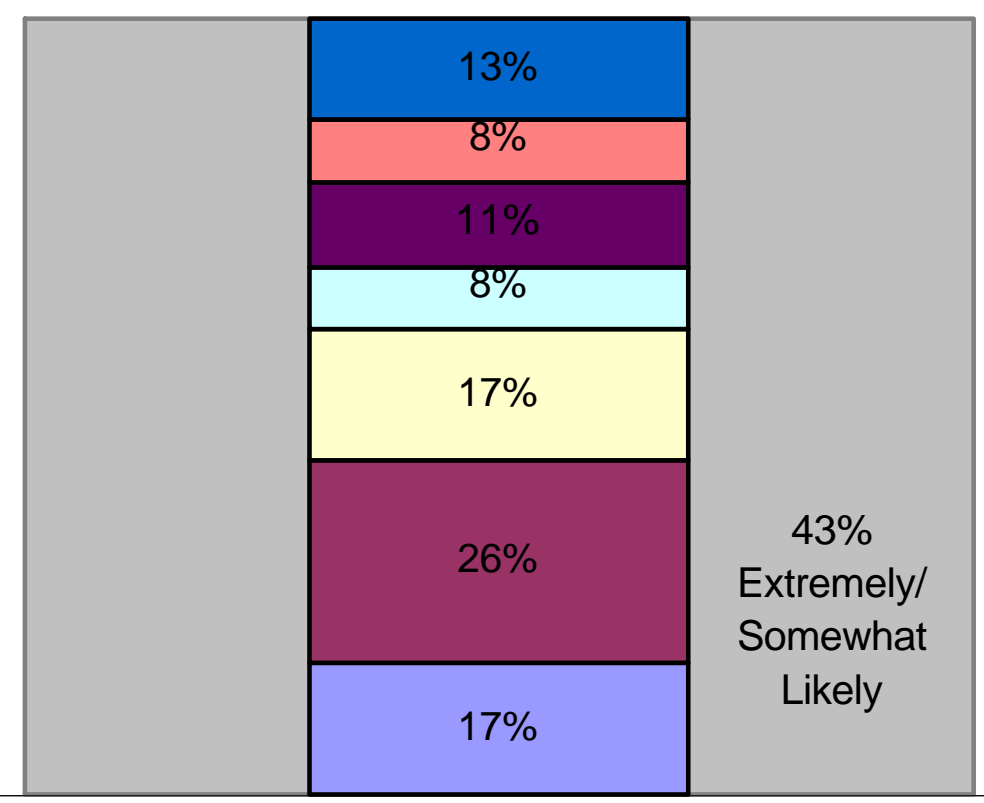

Don't know

$\square$ We don't heat it

Extremely unlikely

口Somewhat unlikely

$\square$ Might or might not

$\square$ Somewhat likely

口Extremely likely

Q.14: How likely do you think you or your family members would be to use the pool more often if it was less expensive to heat? 


\section{PERCEIVED/ACTUAL COSTS OF INSTALLING SOLAR}

Non-users may have an unrealistic expectation of what it actually costs to install a solar pool heating system. Specifically, solar users indicate that they spent an average of $\$ 3,351$ on their solar systems, while non-users on average perceive that it would cost $\$ 2,519$ to install an adequate solar pool heating system - over an $\$ 800$ difference.

It should be noted, however, that over four in ten respondents, both users and nonusers, do not know what they spent or what it would cost for a solar pool heating system.

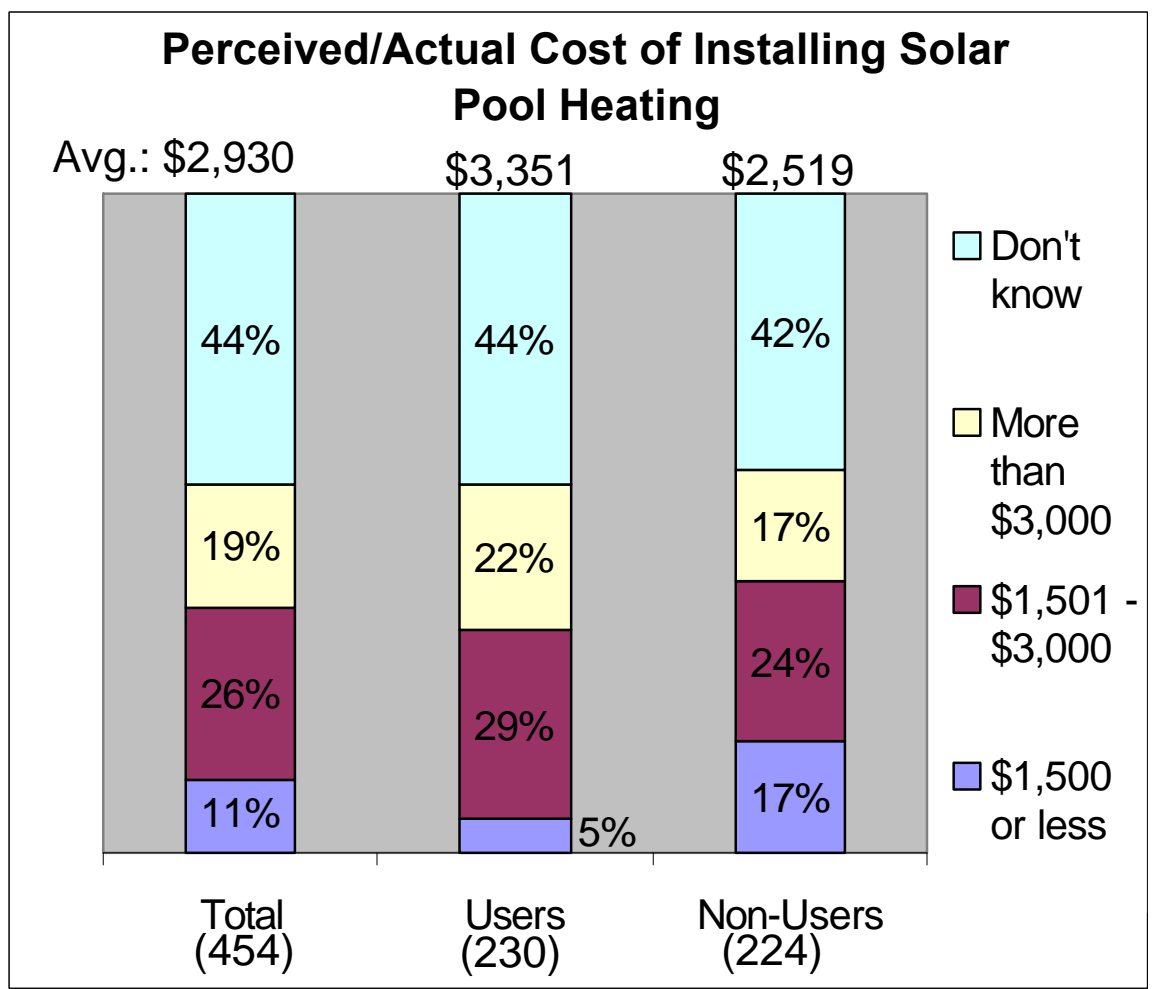

Q.27: (Non-Users) How much do you think it would cost to install a solar pool heating system that would adequately heat your pool? // (Users) How much did you pay to install your solar pool heating system? 


\section{Perceptions of Reasonable Price for Solar System}

While non-users state that they think a solar pool heating system would cost more than $\$ 2,500$ on average, a significantly smaller number represents what they consider to be a reasonable amount. Specifically, non-users feel that a reasonable price for a solar pool heating system would be $\$ 1,388$ on average, with those in California quoting significantly higher prices than do those in Arizona and Florida.

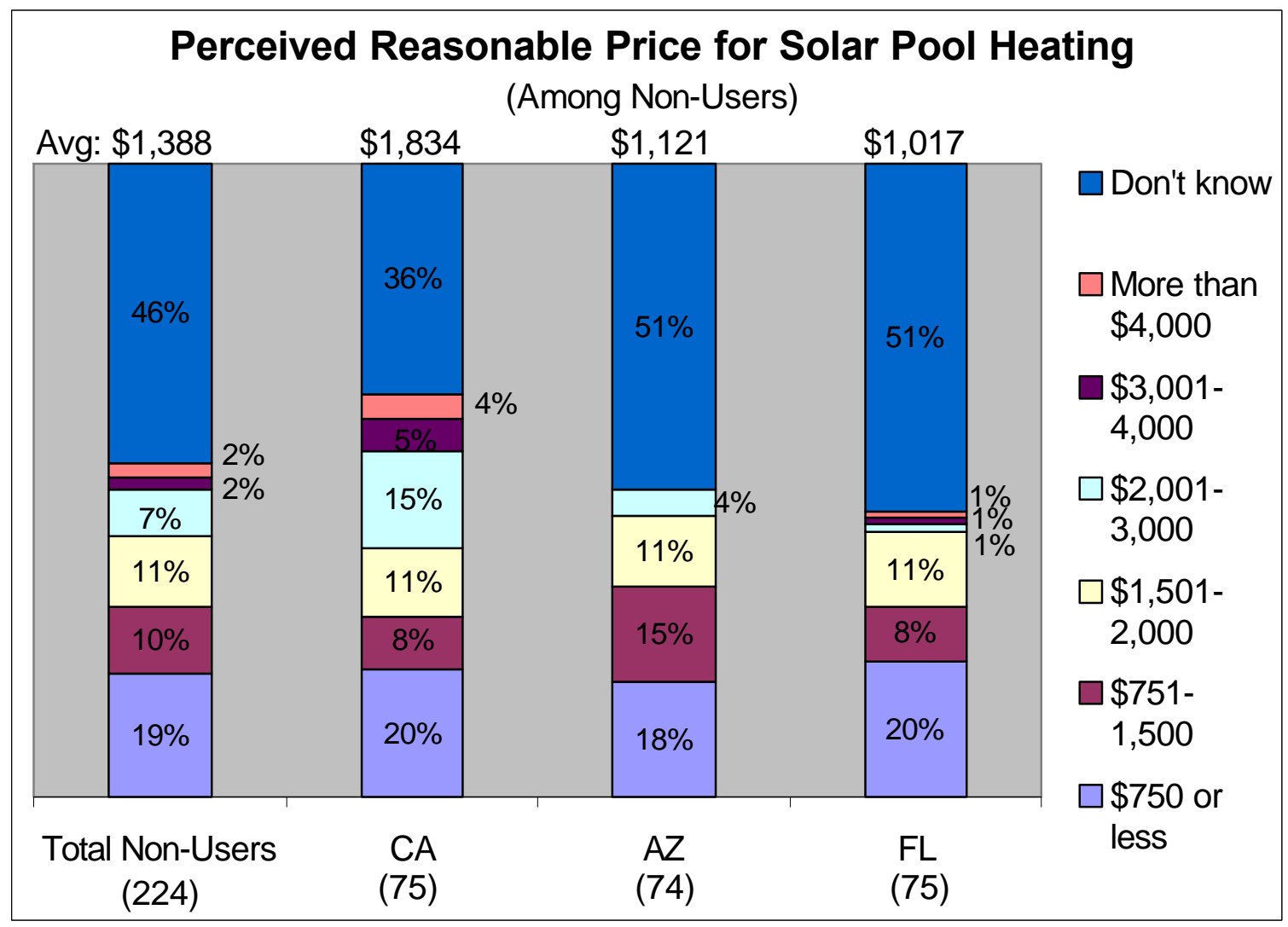

Q.28: What do you think a reasonable price for a solar pool heating system would be? 
Advertising, book/magazines, direct mail and word-of-mouth are the key sources of solar pool heating awareness.

While prolonging the swimming season is the key reason users added solar, the key advantage of solar noted by both users and non-users is money savings. Energy savings, and longer swimming season are secondary advantages. And while solar users do enjoy a longer swimming season than non-users, about a third complain that a disadvantage to solar is that it only works a small part of the year. Non-users clearly see the key disadvantage to solar being the cost of installation.

\section{SOURCE OF SOlAR PoOl HEATING AWARENESS}

Advertising and books/magazines are clearly the key sources of solar pool heater awareness, followed closely by direct mail and word-of-mouth. This is true among both users and non-users. About one-fourth of the respondents are aware of solar pool heating from one or more of these types of sources.

Only about one in ten (13\%) of the solar users states that they heard about solar pool heating from their builder.

Just over one in ten (13\%) non-users indicate that they are not aware of solar pool heating. 


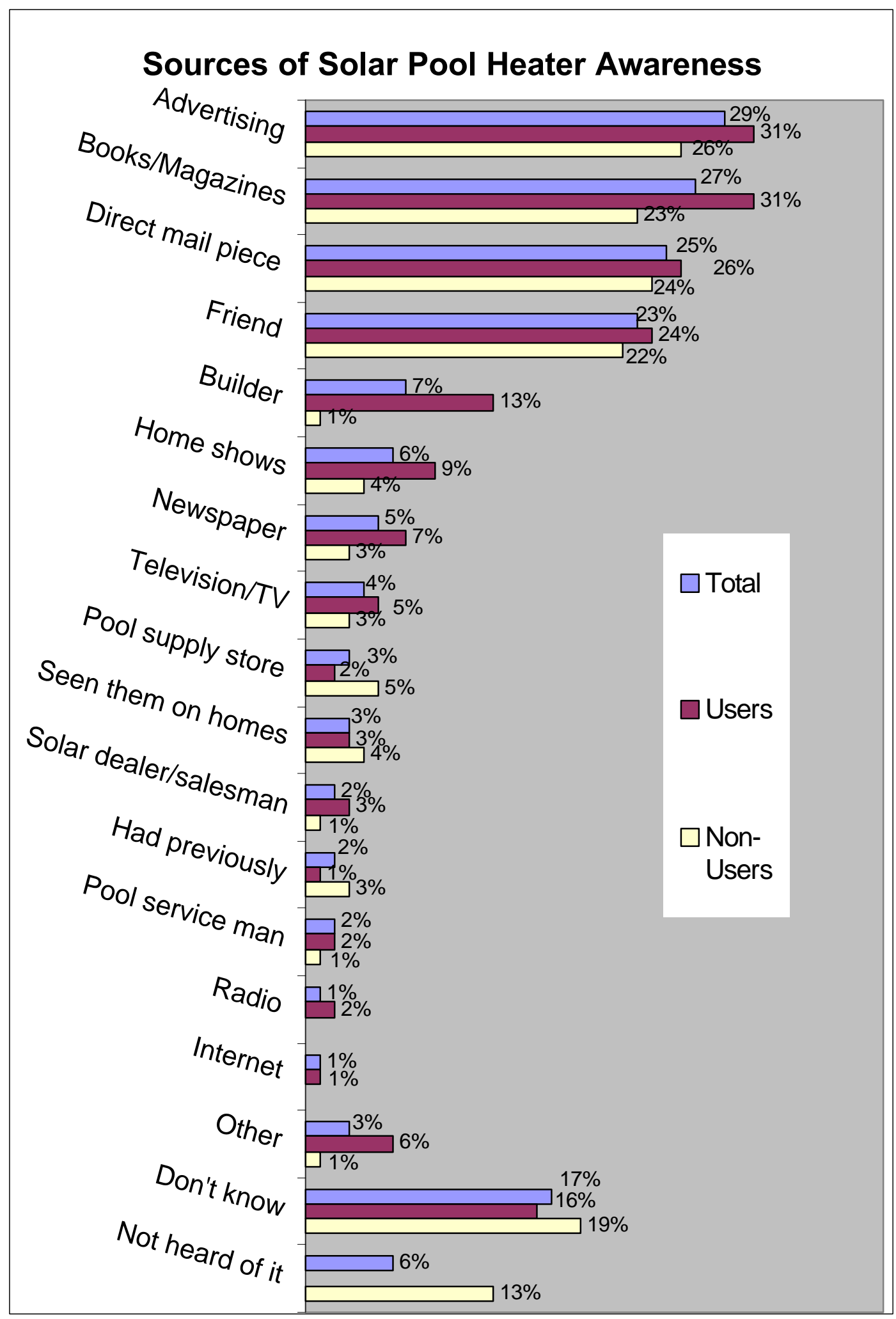

Q.24: Please tell me all of the places or sources where you have heard anything about solar pool heating? 


\section{Perceived Advantages of Solar Pool Heating}

Both solar users and non-users agree that the overwhelming advantage to using a solar pool heater is to save money, with a significantly greater portion of users noting this advantage versus non-users ( $77 \%$ and $58 \%$ respectively).

Around one in five respondents also acknowledge that using less gas/electricity (23\%), having the ability to use their pool longer (19\%) and helping the environment (17\%) are also advantages of using a solar pool heater.

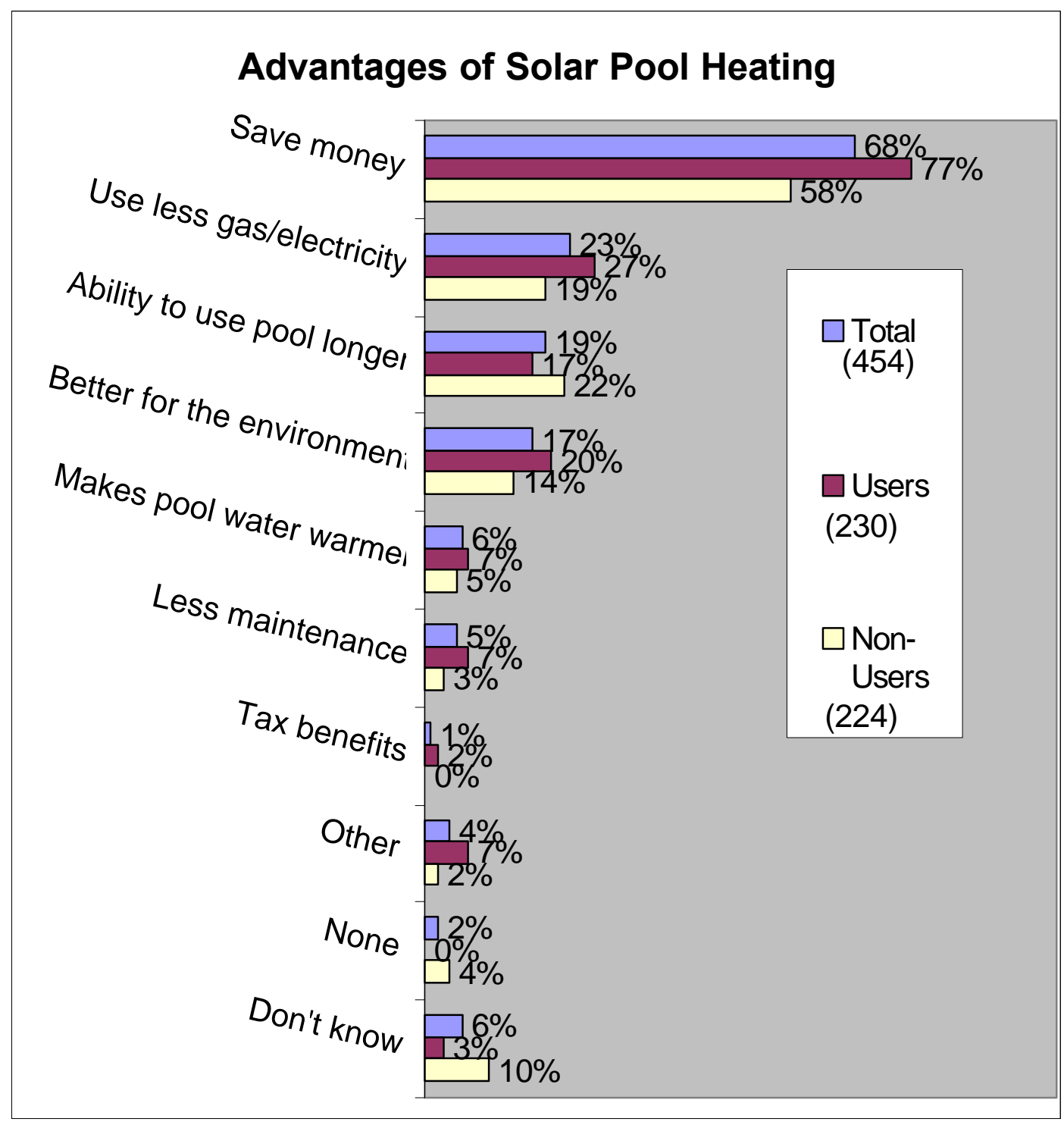

Q.25: What do you think the advantages of using solar energy to help heat the water in your pool would be? 


\section{Perceived Disadvantages of Solar PoOl HEating}

Over four in ten solar users $(41 \%)$ feel that there are no disadvantages to having solar pool heating. However, one-third (32\%) of the users note that a disadvantage to solar is that it only works a small part of the year. Perhaps these solar users are comparing solar pool heating to gas or electric heaters that can fully heat pools year around.

The key disadvantages of solar pool heating perceived by non-users is that it is too expensive to install (29\%) and is unattractive (17\%).

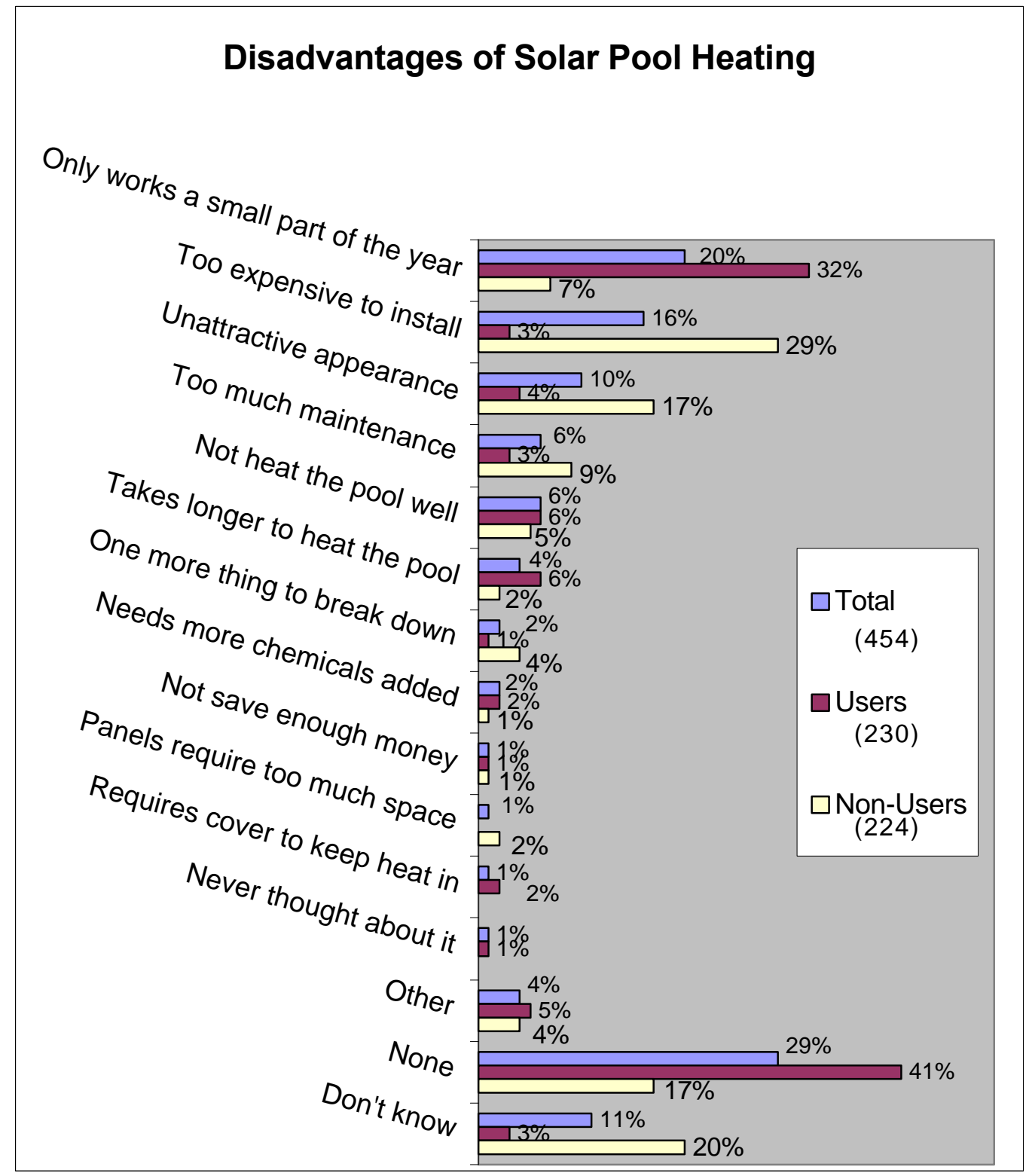

Q.26: What do you think the disadvantages of using solar energy to help heat the water in your pool would be? 
While over a third of the non-users have considered solar pool heating, they decide against it due to the installation costs. Similarly, non-users who have not considered solar also feel that the installation costs are too high.

Despite the resistance to the installation costs, almost all solar users would select it again, and four in ten non-users indicate they would install it if they were to move to a new home that needed a pool heater. Reasons for this future interest in solar are primarily that it costs less to maintain, and secondarily that it is more energy efficient.

\section{NON-USERS EVER CONSIDERED SOLAR}

One-third of the non-users in total indicate that they have considered solar pool heating at some point. Non-users in California are significantly more likely to have considered solar pool heating than those in Arizona and Florida ( $51 \%$ versus $30 \%$ and $25 \%$ ). This may in part be due to the fact that the warm weather season, especially at night, is naturally longer in Arizona and Florida than in California, and many of these respondents do not heat their pools at all.

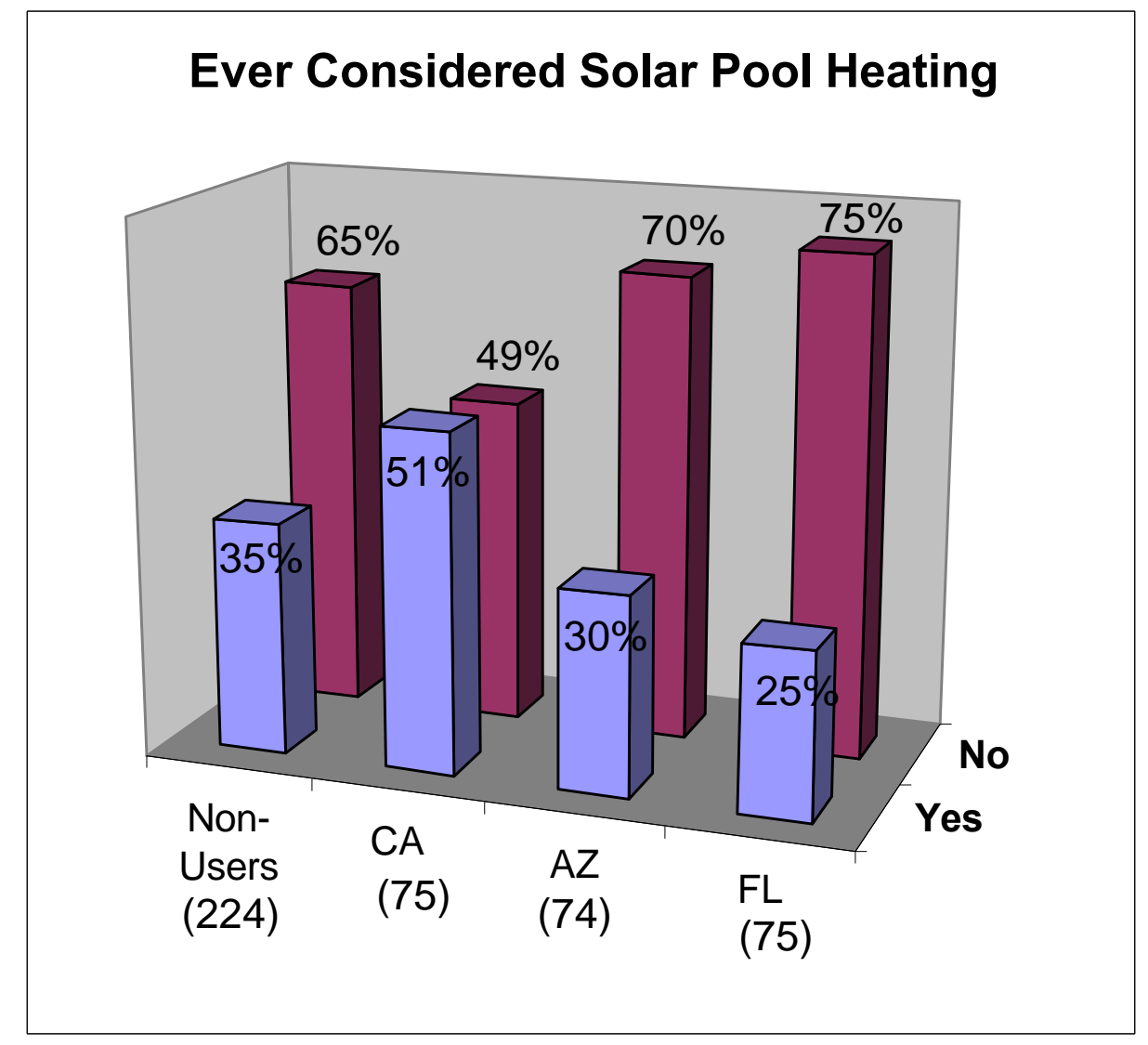

Q.21: Have your ever considered installing solar pool heating? 


\section{REASONS FOR NOT SELECTING / NOT CONSIDERING SOLAR}

Among the non-users who did consider solar pool heating, the primary barrier to purchase is that the systems are too expensive to install (48\%). About one-fifth (18\%) have some specific problem with solar, primarily the appearance (8\%), and one in ten simply "did not

Among the non-users who have not considered solar pool heating, just over three in ten $(32 \%)$ feel it does not offer a good enough cost/value. And almost three in ten (28\%) simply feel they have no need for a solar heater.

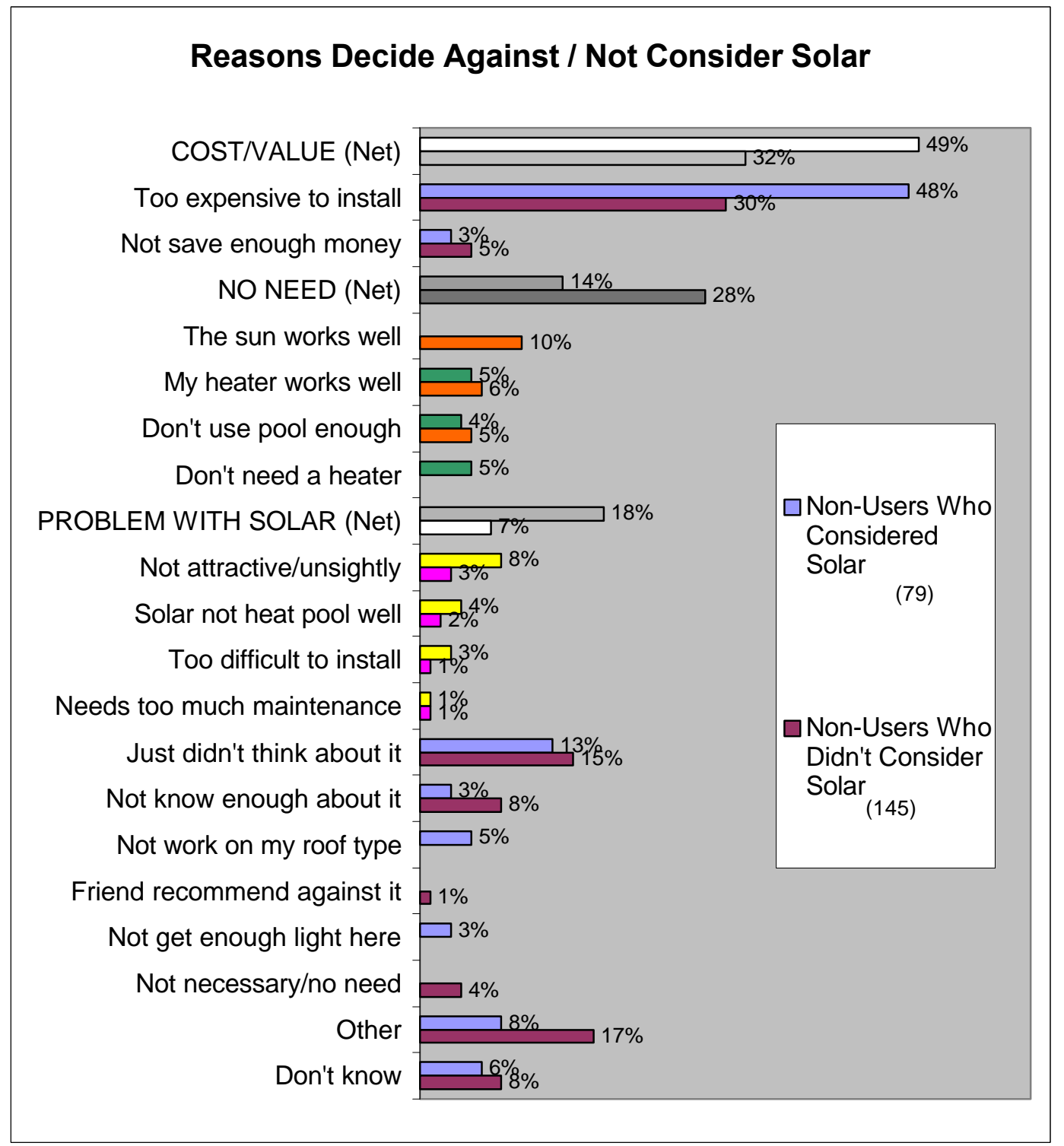

Q.22/23: Why did you decide against purchasing a solar pool heating system? // Why did you not consider a solar pool heater for your home? 


\section{TYPE OF POOL HEATER MOST LIKELY TO INSTALL IN NEW HOME}

Solar users appear to be extremely satisfied, with almost nine in ten (87\%) indicating that they would be most likely to install a solar pool heater again if they were to move into a new home that needed a new pool heater.

Interestingly, four in ten (40\%) non-users feel they would be most likely to install a solar pool heater in their new home as well, with an additional two in ten (23\%) indicating that they are not sure what they would install. However, one fifth of the non-users (20\%) state that they would not heat their new pools at all.

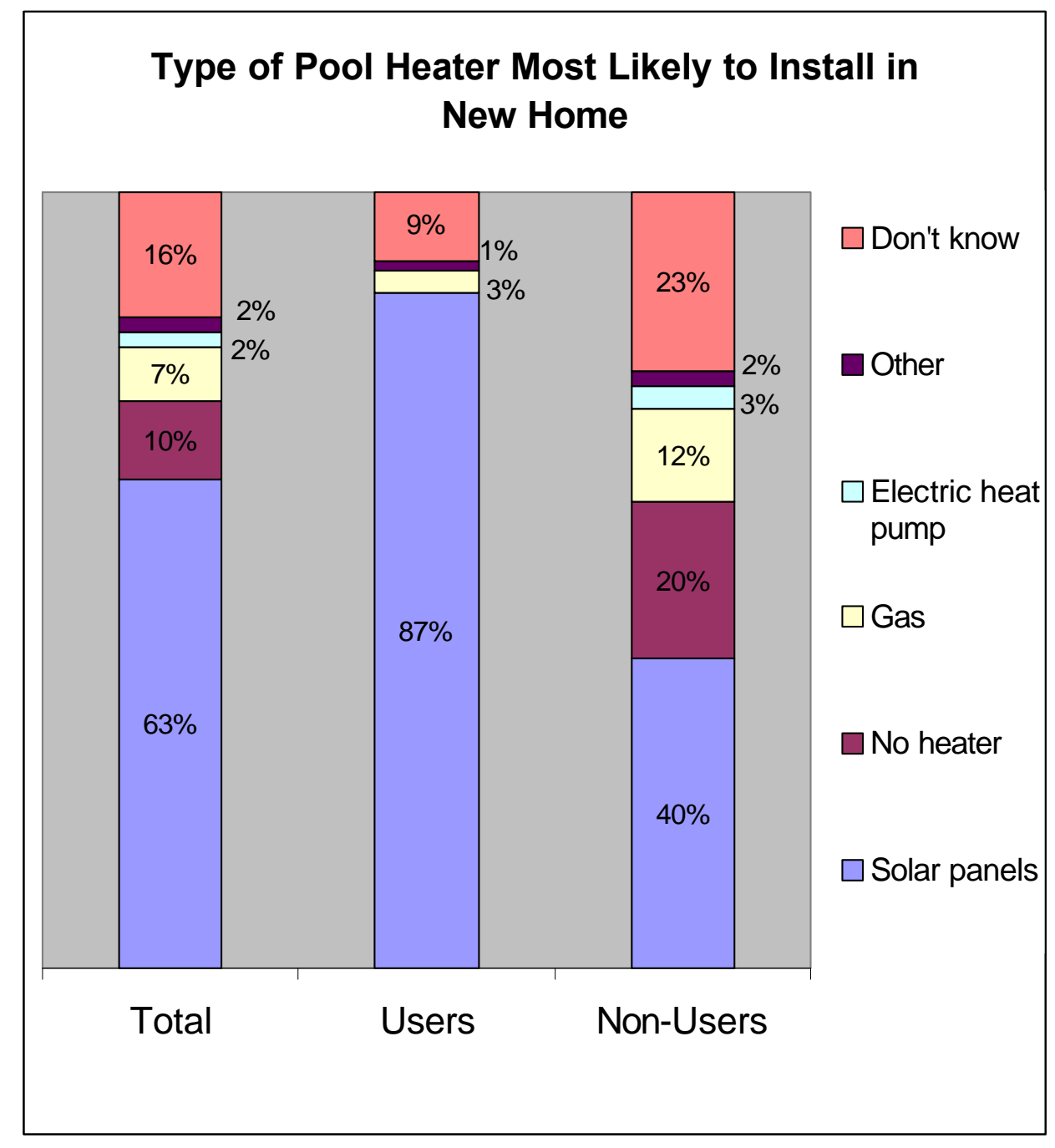

Q.29: If you were to move into a new home that had a pool, but needed a new heater, what type of heating system would you be most likely to install? 


\section{REASONS FOR SELECTING (TYPE) OF HEATER}

Among those who would be most likely to install a solar pool heater, the primary reason for doing so is because it costs less to install and maintain (58\%), with the secondary reason being energy efficiency $(20 \%)$.

Those who are most likely to install gas pool heaters feel that the gas heaters cost less to install and maintain (30\%), and/or they heat the pool better (21\%).

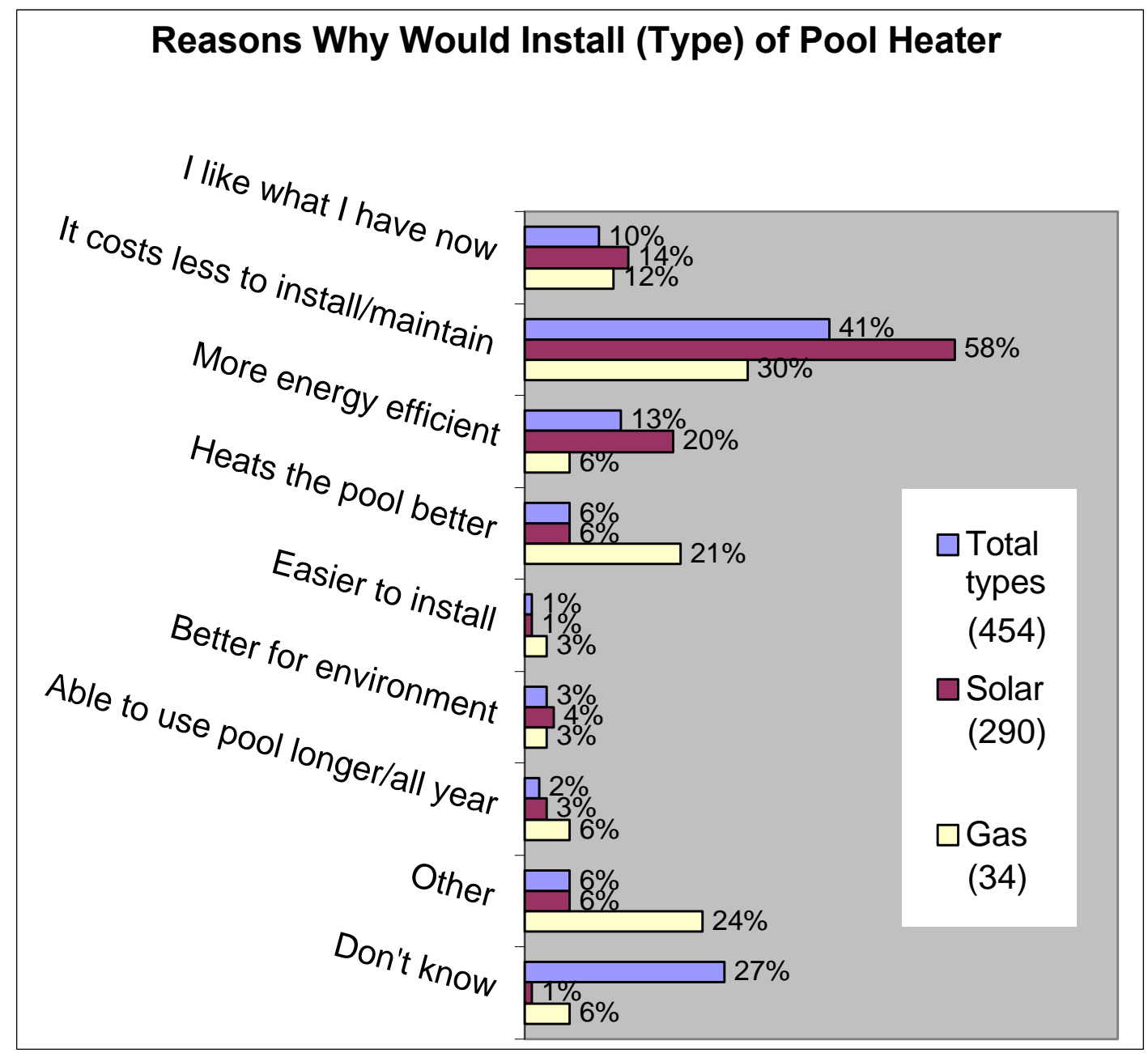

Q.30: Why would you be most likely to purchase a (type in Q.29) heater? 
Both current users and non-users clearly agree that their main reason for preferring solar pool heating is because it costs less to install and maintain (56\% and $61 \%$ respectively). However, non-users focus on the energy savings significantly more than the users do, whereas the users more often note being happy with what they currently have.

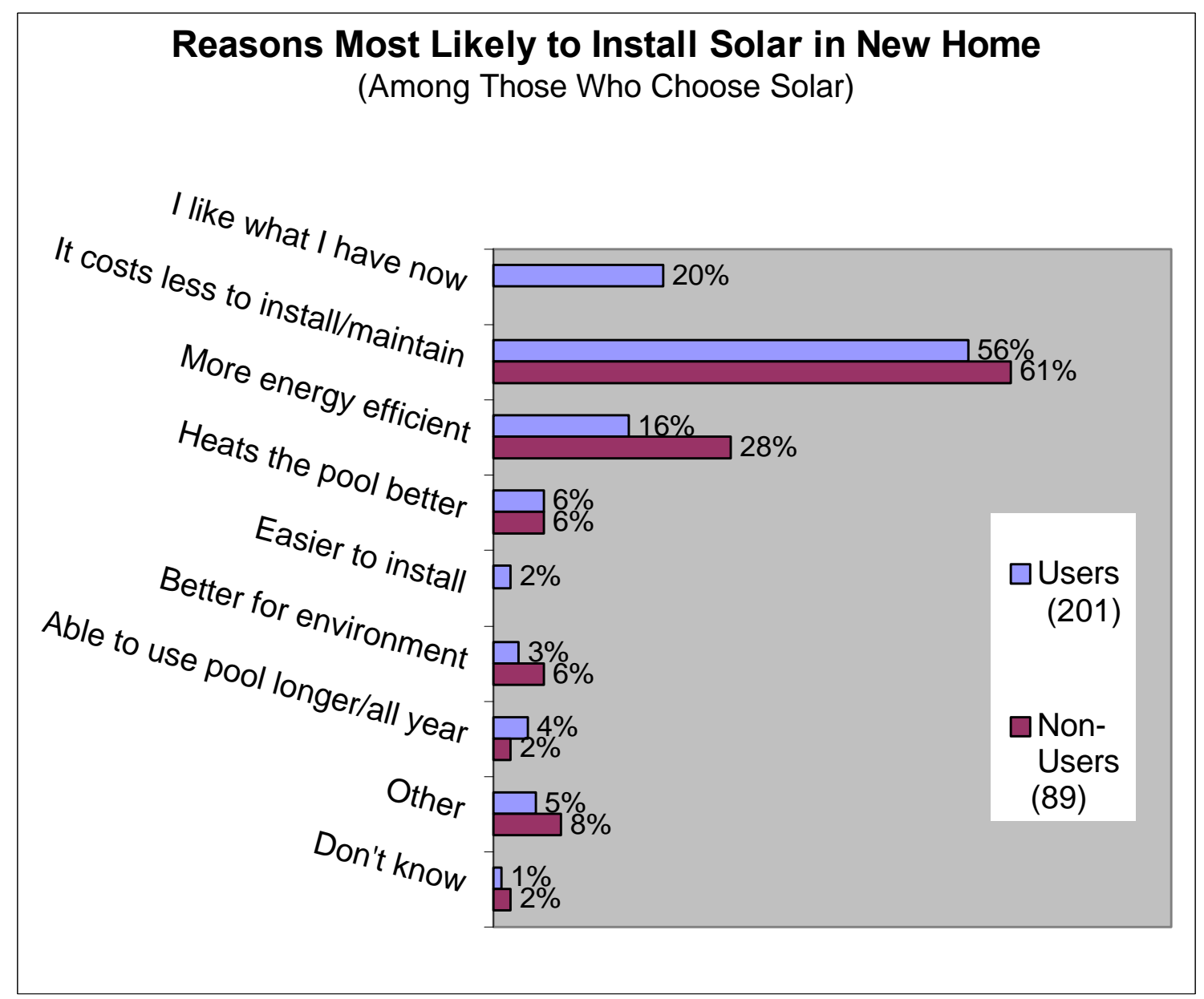

Q.30: Why would you be most likely to purchase a (type in Q.29) heater? 


\section{LIKELIHOOD OF INSTALLING SOLAR}

A substantial portion of the non-users appear to be very resistant to the concept of solar pool heating. Among the non-users who would not be likely to install a solar pool heater in a new home, only a small portion (15\%) indicate that they would even be likely to entertain the idea of a solar pool heater.

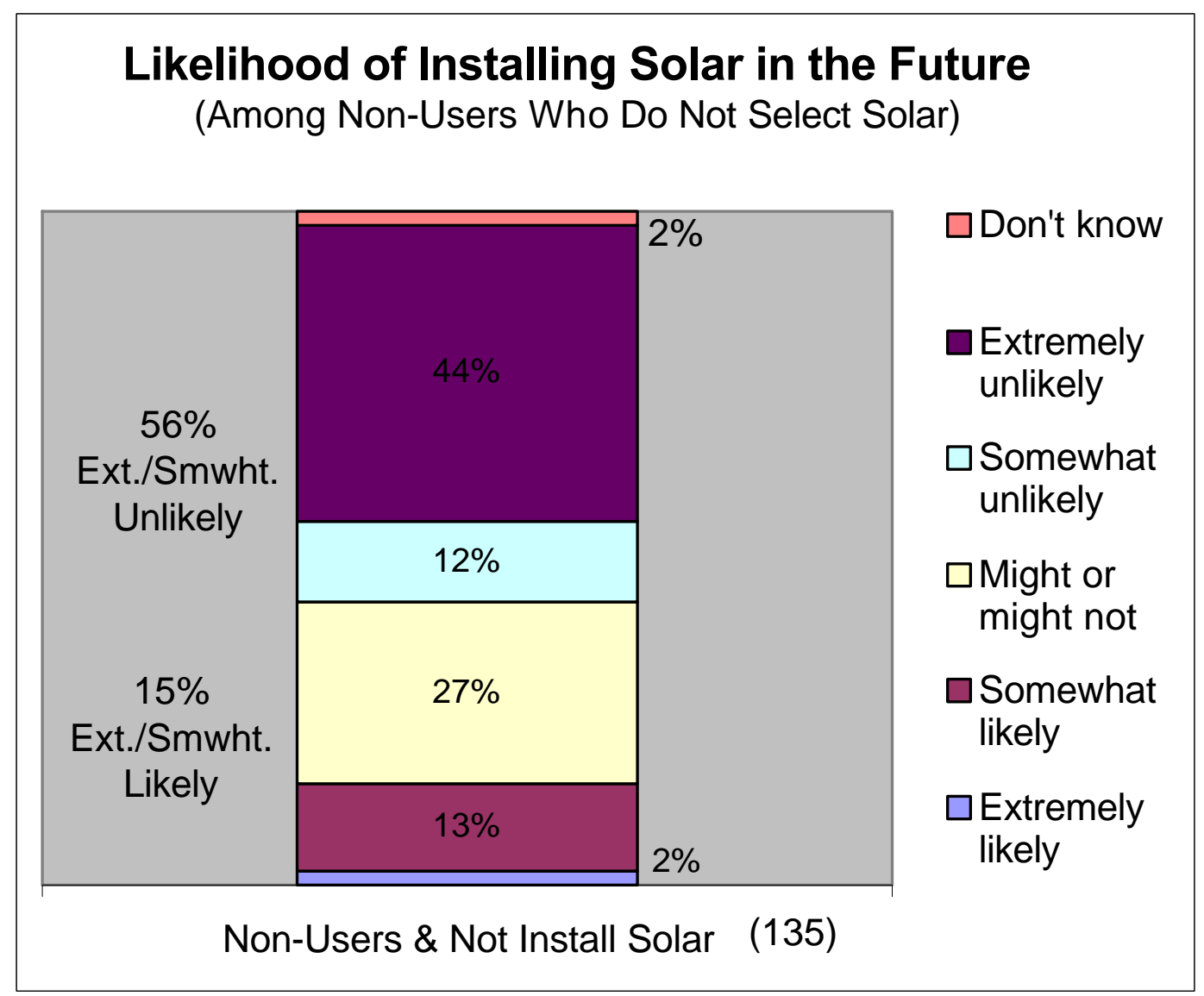

Q.31: How likely would you be to consider installing solar pool heating on this pool or any other pool you may own at some point in the future? 
Overall, it appears that solar users are significantly older, more affluent and live in larger, more valuable homes than non-users. This is true more so among those in California and Arizona than among those in Florida.

\section{HOMES}

Non-users were screened to have lived in their current homes between one and five years. The large majority of solar users have also lived in their homes one to five years.

The average home size is just over 2,400 square feet, and valued just over $\$ 240,000$. Solar users have larger, more expensive homes than non-users on average. While home sizes among respondents in California are only slightly larger than those in Arizona and Florida, the home values in California are significantly higher than in the other states among both solar users and non-users.

\begin{tabular}{|c|c|c|c|c|c|c|c|c|c|}
\hline & & \multicolumn{4}{|c|}{ Solar Users } & \multicolumn{4}{|c|}{ Solar Non-Users } \\
\hline & $\frac{\text { Total }}{(454)}$ & $\begin{array}{l}\text { Total } \\
\text { (230) }\end{array}$ & $\begin{array}{r}\text { CA } \\
\text { (79) }\end{array}$ & $\begin{array}{r}A Z \\
(76)\end{array}$ & $\begin{array}{r}\text { FL } \\
(75)\end{array}$ & $\begin{array}{l}\text { Total } \\
(224)\end{array}$ & $\begin{array}{r}\text { CA } \\
(75)\end{array}$ & $\begin{array}{r}\text { AZ } \\
(74)\end{array}$ & $\begin{array}{l}\text { FL } \\
(75)\end{array}$ \\
\hline \multicolumn{10}{|l|}{ Length of Home Ownership } \\
\hline $1-5$ years & $83 \%$ & $66 \%$ & $51 \%$ & $66 \%$ & $83 \%$ & $100 \%$ & $100 \%$ & $100 \%$ & $100 \%$ \\
\hline $6-9$ years & 5 & 10 & 10 & 10 & 8 & - & - & - & - \\
\hline 10 or more years & 12 & 24 & 39 & 24 & 9 & - & - & - & - \\
\hline \multicolumn{10}{|l|}{ Home Size } \\
\hline$\overline{\text { Under } 1,500 \text { sq. ft. }}$ & 6 & 3 & 1 & 5 & 3 & 9 & 11 & 12 & 3 \\
\hline $1,500-2,599$ sq. ft. & 57 & 57 & 53 & 59 & 58 & 56 & 60 & 52 & 57 \\
\hline $2,600-3,599$ sq. ft. & 29 & 31 & 35 & 25 & 32 & 27 & 17 & 32 & 33 \\
\hline 3,600 sq. ft. or more & 8 & 9 & 11 & 11 & 7 & 8 & 12 & 4 & 7 \\
\hline Average square feet (100's): & 24.4 & 25.1 & 26.1 & 24.6 & 24.5 & 23.7 & 23.5 & 22.9 & 24.7 \\
\hline \multicolumn{10}{|l|}{ Home Value } \\
\hline Under $\$ 100,000$ & 8 & 6 & - & 5 & 10 & 11 & 3 & 11 & 18 \\
\hline$\$ 100,000-149,999$ & 22 & 17 & 4 & 26 & 22 & 28 & 17 & 41 & 27 \\
\hline$\$ 150,000-199,999$ & 21 & 23 & 15 & 22 & 36 & 20 & 21 & 20 & 18 \\
\hline$\$ 200,000-349,999$ & 29 & 30 & 31 & 36 & 24 & 26 & 26 & 23 & 31 \\
\hline$\$ 350,000-499,999$ & 10 & 13 & 27 & 7 & 4 & 6 & 9 & 4 & 6 \\
\hline$\$ 500,000$ or more & 10 & 11 & 23 & 4 & 4 & 9 & 24 & 1 & - \\
\hline Average home value $(\$ 000)$ : & 241.5 & 264.5 & 359.3 & 223.2 & 201.5 & 218.7 & 297.9 & 177.5 & 177.9 \\
\hline
\end{tabular}




\section{DEMOGRAPHICS}

Respondents in this survey were split between male and female, were in their late forties on average, with three in the household on average. The majority of those with children in the household have young children, with the average age of child being just over six years. Over half of these respondents are college graduates or more who have an average household income of over eighty thousand dollars a year.

When looking at demographic differences between solar users and non-users, it appears that the solar users in this sample are older, with higher educational and income levels, and are less often with children in the household. This is the case more so across users versus non-users in California, than across those in Arizona and Florida.

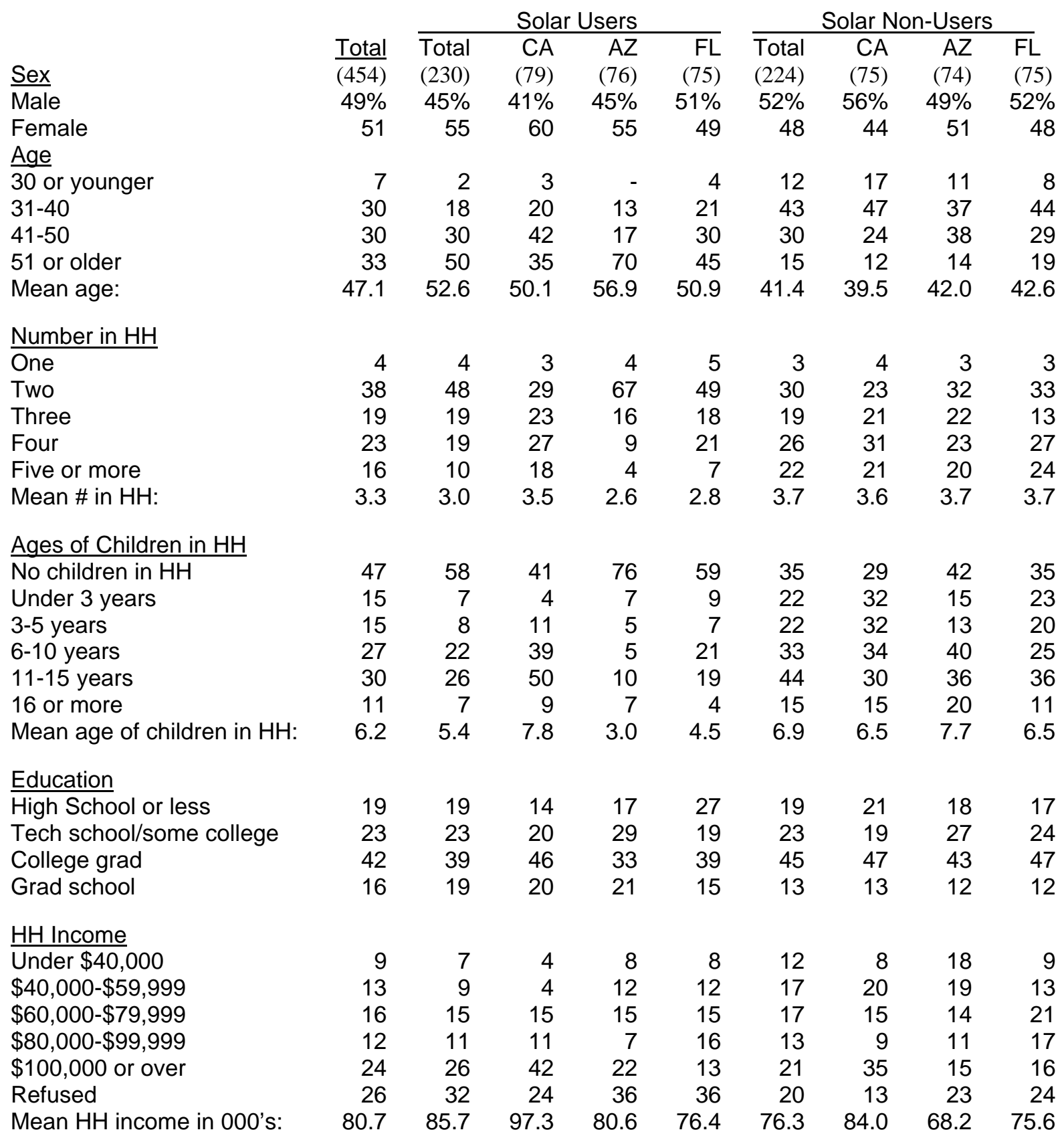




\section{APPENDIX}

- Questionnaires 


\begin{tabular}{|lrr|}
\hline Market & Non-Users & Users \\
\hline Florida & $($ ) & $($ ) \\
Arizona & $($ ) & $($ ) \\
California & $($ ) & $($ ) \\
\hline
\end{tabular}

(I.D. Number)

SCREENING QUESTIONNAIRE

SOLAR POOL HEATING STUDY OCTOBER, 1998

Respondent's Name:

Address:

City/State:

Phone \#:

Interviewed by:

Validated by:

Time Started:

Zip:

Date:

Date:

Time Completed:

Elapsed Time:

ASK TO SPEAK WITH THE NAME ON THE LIST OR THE MALE OR FEMALE ADULT HEAD OF HOUSEHOLD.

Hello, l'm from CRS Research, a national market research firm. We are conducting a survey among homeowners and would like to ask you a few questions. It will only take 12 minutes of your time, and I can assure you that we are not selling anything, and that all of your responses will be strictly confidential.

A. RECORD SEX: (By observation only)
Male
( )
Female
()

B. Do you own the home that you are currently living in?

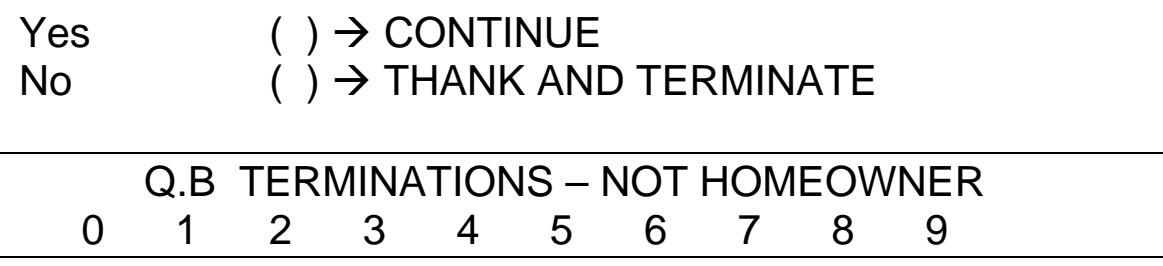


C. Is this home a ...(READ LIST)

Detached single family home

Townhome or condominium
$($ ) $\rightarrow$ CONTINUE

$($ ) $\rightarrow$ THANK AND TERMINATE. CIRCLE NEXT AVAILABLE NUMBER BELOW. ERASE AND REUSE SCREENER.

\begin{tabular}{|cccccccccc|}
\hline \multicolumn{1}{c}{ Q.C } & TERMINATIONS - NOT SINGLE FAMILY \\
0 & 1 & 2 & 3 & 4 & 5 & 6 & 7 & 8 & 9 \\
\hline
\end{tabular}

D. How long have you owned this home?
Less than one year
$($ ) $\rightarrow$ TERMINATE
One to five years
( ) $\rightarrow$ CONTINUE
Longer than five years
( ) $\rightarrow$ THANK AND TERMINATE. CIRCLE NEXT
AVAILABLE NUMBER BELOW. ERASE AND REUSE SCREENER.

\begin{tabular}{|cccccccccc|}
\hline \multicolumn{1}{c|}{ Q.D } & TERMINATIONS - NOT & - 5 & YRS. \\
0 & 1 & 2 & 3 & 4 & 5 & 6 & 7 & 8 & 9 \\
\hline
\end{tabular}

E. Does your home have a swimming pool? (READ LIST AND CHECK ONE.)
Yes
$($ ) $\rightarrow$ CONTINUE
No
( ) $\rightarrow$ THANK AND TERMINATE

\begin{tabular}{cccccccccc}
\multicolumn{1}{c}{ Q.E } & TERMINATIONS - NO POOL \\
0 & 1 & 2 & 3 & 4 & 5 & 6 & 7 & 8 & 9
\end{tabular}

F. What is the type of heating system that you use to heat the water in your pool? (RECORD ALL MENTIONED.)

Natural gas

Electric heat pump

Insulating pool blanket or cover

Not heated

Solar Panels

(DO NOT READ) Do not know
( ) $\rightarrow$ PLACE IN NON-USER QUOTA

( ) $\rightarrow$ PLACE IN NON-USER QUOTA

( ) $\rightarrow$ PLACE IN NON-USER QUOTA

( ) $\rightarrow$ PLACE IN NON-USER QUOTA

( ) $\rightarrow$ PLACE IN USER QUOTA

( ) THANK AND TERMINATE

Q.F TERMINATIONS - NOT KNOW

$\begin{array}{llllllllll}0 & 1 & 2 & 3 & 4 & 5 & 6 & 7 & 8 & 9\end{array}$

IF RESPONDENT REFUSES TO CONTINUE OR QUITS IN THE MIDDLE, TERMINATE. CIRCLE NEXT AVAILABLE NUMBER IN BOX BELOW. ERASE AND REUSE SCREENER.

\begin{tabular}{|llllllllll|l|}
\hline \multicolumn{11}{|c|}{ TERMINATIONS - QBR/BREAKOFF } \\
0 & 1 & 2 & 3 & 4 & 5 & 6 & 7 & 8 & 9 \\
\hline
\end{tabular}




\begin{tabular}{|ll|}
\hline \multicolumn{2}{|c|}{ Market } \\
Florida & $($ ) \\
Arizona & $($ ) \\
California & $($ ) \\
\hline
\end{tabular}

(I.D. Number)

MAIN QUESTIONNAIRE - NON-USERS

SOLAR POOL HEATING STUDY

OCTOBER, 1998

1. Did your home come with a swimming pool, or did you have it built? (READ LIST)

Came with it

$($ ) $\rightarrow$ CONTINUE

Built it

( ) $\rightarrow$ SKIP TO Q.8

2. Did you base the purchase of your home, at least in part, on the fact that it had a swimming pool?
Yes
No

3. SKIP

4. When you purchased your home, did you consider the cost of heating the pool?

$\begin{array}{ll}\text { Yes } & (\text { ) } \\ \text { No } & (\text { ) } \\ \text { Never thought about it } & (\text { ) }\end{array}$

5. SKIP

6. SKIP

7. SKIP

8. In which months do you or your family members use your pool? (CHECK ALL MENTIONED.)
January ........ ( )
February......( )
March ........... ( )
April
May .............( )
June ............( )
July.............( )
August..........( )
September... ( )
October ........ ( )
November.... ( )
December.... ( )

9. During these months, how many days a month do you or a family member use the pool on average? (WRITE IN NUMBER OF DAYS)

Number of days: 
(IF Q.F IS "NOT HEATED”, SKIP TO Q.15)

10. During the months that you use your pool, do you keep your pool heated all of the time, just on days when you are using it, or none of the time?

All of the time

Just when using it

None of the time

Other (Specify:)

11. Now that you've owned your pool for some time, how much do you believe it costs per month to heat your pool during the primary months you use it? (TRY TO GET AN ESTIMATE IF NOT SURE)

Dollars / month: \$

Don't heat it:

Don't know

12. Is this amount more, less, or about what you expected it would be?
More
Less
About what I expected
Don't know
( )
( )
( )
$($ )

13. Would you say the cost of heating your pool causes you to choose not to go swimming in your pool frequently, occasionally, rarely or never?

Frequently

Occasionally

Rarely

Never

14. How likely do you think you or your family members would be to use the pool more often if it was less expensive to heat?

Extremely likely

Somewhat likely

Might or might not

Somewhat unlikely

Extremely unlikely

We don't heat it 
(IF "BUILT" IN Q.1, ASK Q.15 THROUGH Q.20. OTHERWISE SKIP TO Q.21)

15. How many years ago did you build your pool?

$1-2$ years ago

3 - 5 years ago

16. When you built this pool how did you decide which type of heating to install?

Builder recommended

Friends recommended

Home show

Had this in my previous pool... ( )

Builder chose heating type ...... ( )

Other (Specify)

17. When you were planning your pool purchase, did the pool builder discuss the cost of heating your new pool with you?

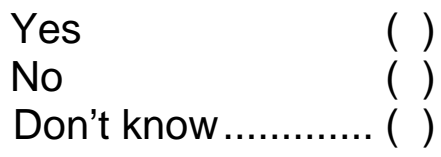

18. Did your builder discuss solar heating with you?

Yes ….... ( ) $\rightarrow$ ASK Q.19

No $\ldots . . . . .(~) \rightarrow$ SKIP TO Q.20

19. What did your builder tell you about solar pool heating?

20. How likely would you have been to install a solar pool heating system if your builder had recommended it to you?

I would have seriously considered installing a solar pool heater I would have wanted to learn more about solar pool heating, or I would probably not have considered installing a solar pool heater

(ASK ALL)

21. Have you ever considered installing solar pool heating?

Yes ….... ( ) $\rightarrow$ ASK Q.22

No $\ldots . . . . .($ ( ) $\rightarrow$ SKIP TO Q.23 
22. Why did you decide against purchasing a solar pool heating system? (CHECK ALL THAT APPLY, THEN SKIP TO Q.24)

My heater works well / OK................................... ( )

Just didn't think about it....................................... ( )

Too expensive to purchase and install ................... ( )

Not attractive / unsightly .................................... ( )

Builder never mentioned it.................................. ( )

Builder recommended against it........................... ( )

Friend recommended against it........................... ( )

Too difficult to install............................................ ( )

Not save any/enough money............................... ( )

Was not comfortable with the contractor ................. ( )

Solar will not heat my pool well ............................. ( )

Solar breaks too often/ too much maintenance...... ( )

Do not know enough about it................................ ( )

Other (Specify)

Don't know

23. Why did you not consider a solar pool heater for your home? (CHECK ALL THAT APPLY)

My heater works well / OK................................... ( )

Just didn't think about it....................................... ( )

Too expensive to purchase and install ................... ( )

Not attractive / unsightly ..................................... ( )

Builder never mentioned it................................... ( )

Builder recommended against it............................ ( )

Friend recommended against it............................ ( )

Too difficult to install............................................... ( )

Not save any/enough money................................. ( )

Was not comfortable with the contractor ................ ( )

Solar will not heat my pool well .............................. ( )

Solar breaks too often/ too much maintenance ....... ( )

Do not know enough about it................................. ( )

Other (Specify)

Don't know 
24. Please tell me all of the places or sources that where you have heard anything about solar pool heating? (CHECK ALL THAT ARE MENTIONED)

Not heard of it

Builder

Have seen them on homes ... ( )

Friend

Books/magazines

Internet

Direct mail piece.....................( )

Advertising....

Home shows

Other

Don't know.

25. What do you think the advantages of using solar energy to help heat the water in your pool would be? What other advantages would there be?

Save money

Use less gas/electricity....

Better for the environment

Tax benefits

Other (Specify)

None

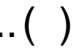

Don't know.

26. What do you think the disadvantages of using solar energy to help heat the water in your pool would be? What other disadvantages would there be?

Only works a small part of the yr./during Summer.. ( )

Units do not look good on homes/appearance.....

Too much maintenance.

One more piece of equipment to break down......... ( )

Not heat the pool well.

Takes longer heat the pool

Too expensive to install

Not save any / enough money

Never thought about it.

Other (Specify)

None

Don't know 
27. How much do you think it would cost to install a solar pool heating system that would adequately heat your pool? (WRITE IN DOLLAR AMOUNT)

(Amount) \$

Not sure / don't know... ( )

28. What do you think a reasonable price for a solar pool heating system would be?

(Amount) \$

Not sure / don't know.. ( )

29. If you were to move into a new home that had a pool, but needed a new heater, what type of heating system would you be most likely to install?

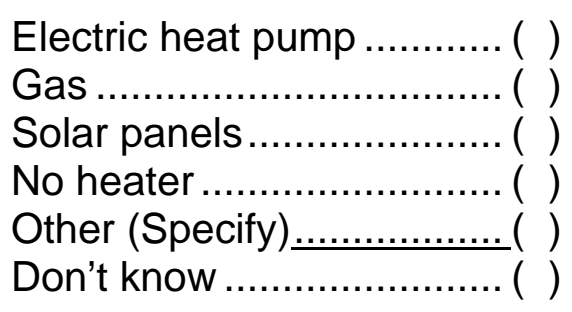

30. Why would you be most likely to purchase a (type in Q.29) heater?

I like what I have now.

It costs less to install and maintain

It is more energy efficient.

It heats the pool better

It's easier to install

Other (Specify:)

(ASK IF NOT SOLAR IN Q. 29. OTHERWISE SKIP TO Q.32)

31 . How likely would you be to consider installing solar pool heating on this pool or any other pool you may own at some point in the future? (READ LIST)

Extremely likely ................ ( )
Somewhat likely ............. ( )
Might or might not ............ ( )
Somewhat unlikely ............ ( )
Extremely unlikely ............ ( ) 
Now, l'd like to ask you some questions to help us classify you with the other participants in this survey.

32. Please tell me which category best describes your age? (READ LIST)

Under 21 years of age.

21-30 years

$31-40$ years

$41-50$ years

$51-60$ years

$61-70$ years

71 or older

33. Including yourself, how many people are currently living in your household?

One …….................... ( )

Two …….................. ( )

Three .......................... ( )

Four.......................... ( )

Five …….................. ( )

Six or more.................. ( )

34. What are the ages of the children in your household?
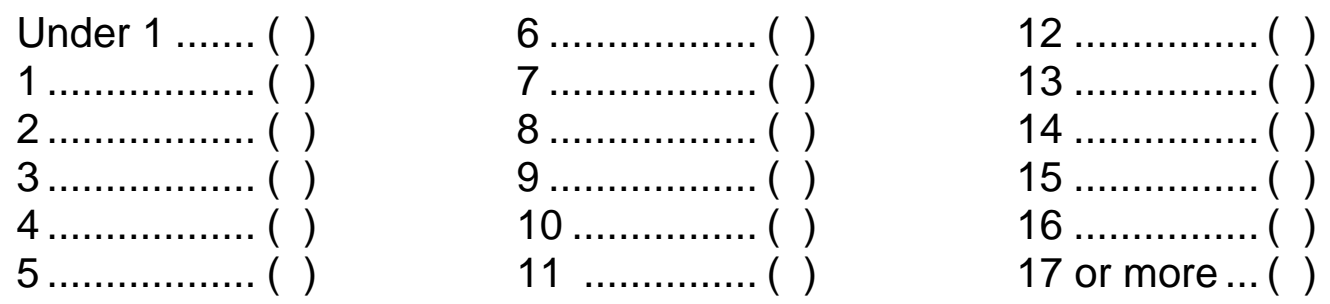

35. What was the last grade of school you completed?

Less than high school graduate

High school grad/GED.

Technical school / trade school

Some college

College grad....

Graduate school.

36. Which of the following best describes the size of your current home? (READ LIST.)

Under 1,500 square feet....( )

$1,500-2,500$ square feet. ( )

$2,600-3,500$ square feet. ( )

$3,600-4,500$ square feet. ( )

Over 4,500 square feet......( ) 
37. Please tell me which of these categories best describes the current value of your home. (READ LIST)

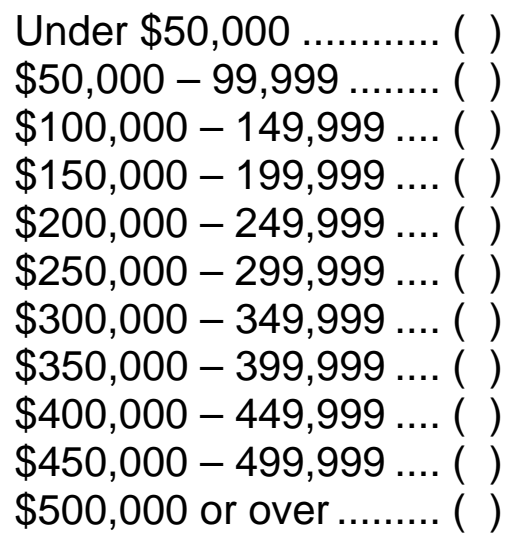

Refused..................... ( ) $\rightarrow$ DO NOT READ

38. Please tell me which of these categories best describes your total annual household income before taxes. (READ LIST)

Under $\$ 20,000$

$\$ 20,000-29,999$

$\$ 30,000-39,999$

$\$ 40,000-59,999$

$\$ 60,000-79,999$

$\$ 80,000-99,999$

$\$ 100,000$ or over

Refused

( ) $\rightarrow$ DO NOT READ

THANK YOU VERY MUCH FOR PARTICIPATING IN THIS SURVEY! 


\section{Market}

Florida

Arizona

California

\section{( )}

( )

( )

(I.D. Number)

\section{MAIN QUESTIONNAIRE - USERS}

SOLAR POOL HEATING STUDY

OCTOBER, 1998

1. Did your home come with your current pool, or did you have this pool built? (READ LIST)

Came with it

Built it

2. SKIP

3. Was your solar pool heating system installed when the pool was built, or was it added later?

Added later....... $\quad($ ) $\rightarrow$ CONTINUE

Installed when pool was built ()$\rightarrow$ SKIP TO Q.8

Don't know ....... $\quad($ ) $\rightarrow$ SKIP TO Q.8

4. SKIP

5. How many years ago did you add your solar pool heating system?

1-2 years ago

3-5 years ago

6. Why did you have a solar pool heating system installed?

The old one broke/was not working

The old one did not heat the pool well

The old one cost too much to use

Other (Specify:)

7. Now that you have a new pool heating system, do you find that you use your pool...(READ LIST)

A lot more often

A little more often

About the same amount .......... ( )

A little less often ...................... ( )

A lot less often 
8. In which months do you or your family members use your pool? (CHECK ALL MENTIONED.)
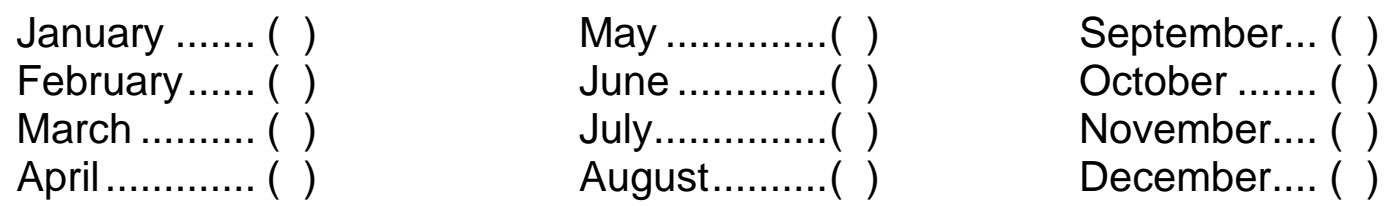

9. During these months, how many days a month do you or a family member use the pool on average? (WRITE IN NUMBER OF DAYS)

Number of days:

10. During the months that you use your pool, do you keep your pool heated all of the time, just on days when you are using it, or none of the time?

All of the time

Just when using it

None of the time

Other (Specify:)

11. Now that you've owned your pool for some time, how much do you believe it costs per month to heat your pool during the primary months you use it? (TRY TO GET AN ESTIMATE IF NOT SURE)

Dollars / month: \$

Don't heat it:

Don't know

( )

12. Is this amount more, less, or about what you expected it would be?

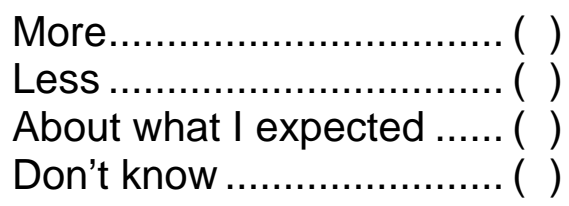

13. Would you say the cost of heating your pool causes you to choose not to go swimming in your pool frequently, occasionally, rarely or never?

Frequently

Occasionally

Rarely

Never

\section{SKIP}


(IF "BUILT" IN Q.1, ASK Q.15-19. OTHERWISE SKIP TO Q.24)

15. How many years ago did you build your pool?

1-2 years ago

3-5 years ago

16. When you built this pool how did you decide which type of heating to install?

Builder recommended

Friends recommended

Home show

Builder chose heating type ...... ( )

Had this in my previous pool .. ( )

Other (Specify)

17. When you were planning your pool purchase, did the pool builder discuss the cost of heating your new pool with you?

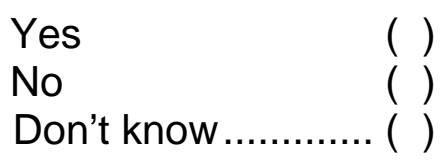

18. Did your builder discuss solar heating with you?

Yes ........ ( ) $\rightarrow$ ASK Q.19

No $\ldots . . . . .($ ( ) $\rightarrow$ SKIP TO Q.24

19. What did your builder tell you about solar pool heating?

20. SKIP

21. SKIP

22. SKIP

23. SKIP

24. Please tell me all of the places or sources where you have heard anything about solar pool heating? (CHECK ALL THAT ARE MENTIONED)

Not heard of it.

Builder

Have seen them on homes ... ( )

Friend

Books/magazines

Internet

Direct mail piece

Advertising.

Home shows.

Other

Don't know.... 
25. What do you think the advantages of using solar energy to help heat the water in your pool are? What other advantages are there?

Save money

Use less gas/electricity

Better for the environment

Tax benefits

Other (Specify)

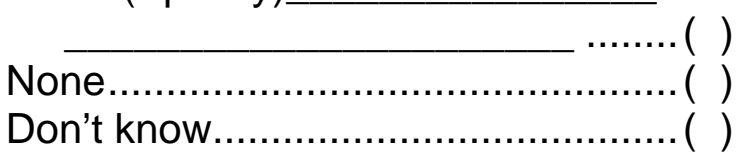

26. What do you think the disadvantages of using solar energy to help heat the water in your pool are? What other disadvantages are there?

Only works a small part of the yr./during Summer.. ( )

Units do not look good on homes/appearance

Too much maintenance.

One more piece of equipment to break down.

Not heat the pool well

Takes longer heat the pool

Too expensive to install

Not save any / enough money

Never thought about it.

Other (Specify)

None.

Don't know

27. How much did you pay to install your solar pool heating system? (WRITE IN DOLLAR AMOUNT)

(Amount) \$

Not sure / don't know... ( )

\section{SKIP}

29. If you were to move into a new home that had a pool, but needed a new heater, what type of heating system would you be most likely to install?

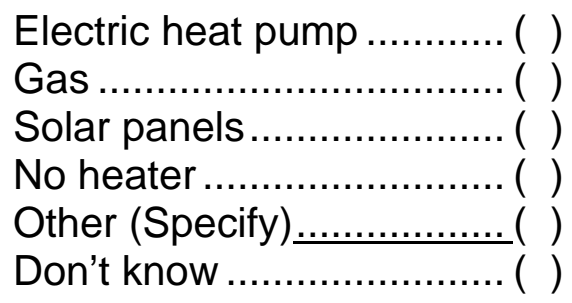


30. Why would you be most likely to purchase a (type in Q.29) heater?

I like what I have now

It costs less to install and maintain

It is more energy efficient

It heats the pool better

It's easier to install

Other (Specify:)

31.SKIP

32. Please tell me which category best describes your age? (READ LIST)

Under 21 years of age. ( )

$21-30$ years

$31-40$ years

$41-50$ years

$51-60$ years

61-70 years

71 or older

33. Including yourself, how many people are currently living in your household?

One

Two

Three

Four.

Five

Six or more

34. What are the ages of the children in your household?
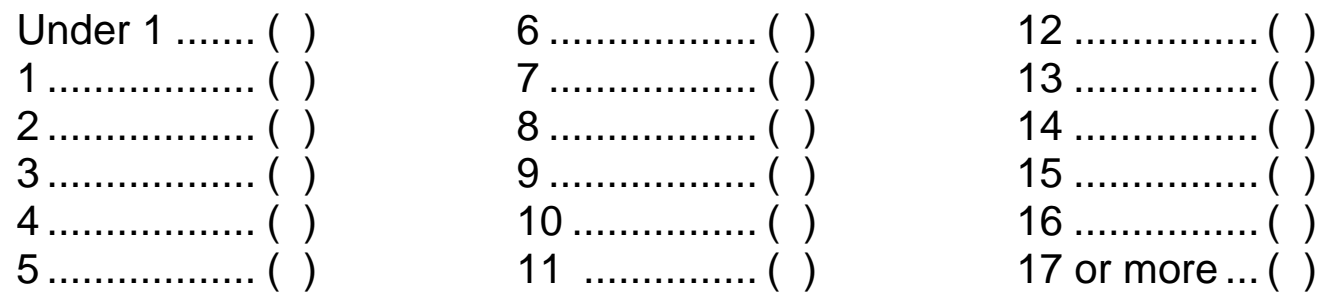

35. What was the last grade of school you completed?

Less than high school graduate

High school grad/GED..

Technical school / trade school

Some college

College grad.

Graduate school 
36. Which of the following best describes the size of your current home? (READ LIST.)

Under 1,500 square feet....( )

$1,500-2,500$ square feet. ( )

$2,600-3,500$ square feet. ( )

$3,600-4,500$ square feet .( )

Over 4,500 square feet......( )

37. Please tell me which of these categories best describes the current value of your home. (READ LIST)

Under $\$ 50,000$

$\$ 50,000-99,999$

$\$ 100,000-149,999 \ldots .($ )

$\$ 150,000-199,999$

$\$ 200,000-249,999$

$\$ 250,000-299,999$

$\$ 300,000-349,999$

$\$ 350,000-399,999$

$\$ 400,000-449,999$

$\$ 450,000-499,999$

$\$ 500,000$ or over

Refused

( ) $\rightarrow$ DO NOT READ

38. Please tell me which of these categories best describes your total annual household income before taxes. (READ LIST)

Under $\$ 20,000$

$\$ 20,000-29,999$

$\$ 30,000-39,999$

$\$ 40,000-59,999$

$\$ 60,000-79,999$

$\$ 80,000-99,999$

$\$ 100,000$ or over

Refused $($ ) $\rightarrow$ DO NOT READ

THANK YOU VERY MUCH FOR PARTICIPATING IN THIS SURVEY! 


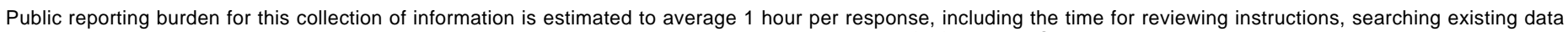

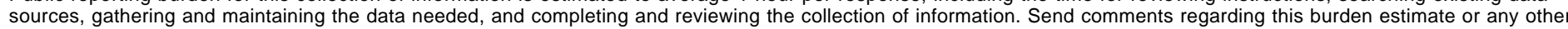

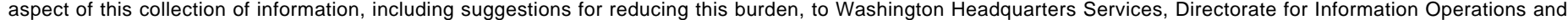

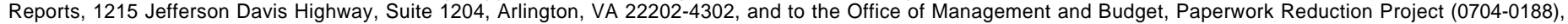
Washington, DC 20503.

\begin{tabular}{|l|l|l}
\hline 1. AGENCY USE ONLY (Leave blank) & $\begin{array}{c}\text { 2. REPORT DATE } \\
\text { January } 1999\end{array}$ & $\begin{array}{l}\text { 3. REPORT TYPE AND DATES COVERED } \\
\text { Subcontract Report }\end{array}$ \\
\hline
\end{tabular}

4. TITLE AND SUBTITLE

Report on Solar Pool Heating Quantitative Survey
5. FUNDING NUMBERS

SH81.7001

6. $\operatorname{AUTHOR}(S)$

Synapse Infusion Group

7. PERFORMING ORGANIZATION NAME(S) AND ADDRESS(ES)

Synapse Infusion Group

4188 Oak Place Drive, Atrium Level

Westlake Village, CA 91362

8. PERFORMING ORGANIZATION

REPORT NUMBER

SR-550-26485

National Renewable Energy Laboratory

1617 Cole Boulevard

Golden, Colorado 80401-3393

9. SPONSORING/MONITORING AGENCY NAME(S) AND ADDRESS(ES)

U.S. Department of Energy

1000 Independence Ave., SW

10. SPONSORING/MONITORING AGENCY REPORT NUMBER

Washington, DC 20585

SR-550-26485

11. SUPPLEMENTARY NOTES

12a. DISTRIBUTION/AVAILABILITY STATEMENT

12b. DISTRIBUTION CODE

National Technical Information Service

U.S. Department of Commerce

5285 Port Royal Road

Springfield, VA 22161

13. ABSTRACT (Maximum 200 words)

This report details the results of a quantitative research study undertaken to better understand the marketplace for solar pool-heating systems from the perspective of residential pool owners.

14. SUBJECT TERMS

pool heating, solar pool heating, water heating, swimming pool

15. NUMBER OF PAGES

50

16. PRICE CODE

17. SECURITY CLASSIFICATION

OF REPORT

unclassified
18. SECURITY CLASSIFICATION OF THIS PAGE unclassified
19. SECURITY CLASSIFICATION OF ABSTRACT unclassified
20. LIMITATION OF ABSTRACT UL 